\title{
Mechanical Transformation of Fly Ash toward Its Utilization in Cemented Paste Backfill
}

\author{
Haijun Wang $\mathbb{1 D}^{1,2}$ and Yun Duan ${ }^{1}$ \\ ${ }^{1}$ BGRIMM Technology Group, Beijing 100160, China \\ ${ }^{2}$ School of Resource and Civil Engineering, Northeastern University, Shenyang 110819, China \\ Correspondence should be addressed to Haijun Wang; wang_hj@bgrimm.com
}

Received 2 May 2021; Revised 12 July 2021; Accepted 2 August 2021; Published 11 August 2021

Academic Editor: Piti Sukontasukkul

Copyright (c) 2021 Haijun Wang and Yun Duan. This is an open access article distributed under the Creative Commons Attribution License, which permits unrestricted use, distribution, and reproduction in any medium, provided the original work is properly cited.

\begin{abstract}
Fly ash (FA) showed low reactivity when being used to prepare the binder for cemented paste backfill (CPB). In the present work, wet-grinding treatment was used to increase the pozzolanic reactivity of FA and promote its sustainable utilization. The results showed that wet-grinding could be a suitable and efficient technology for FA pretreatment. Wet-grinding strongly modified the structure of FA by decreasing the crystalline phase content and the binding energy of $\mathrm{Si} 2 \mathrm{p}$ and $\mathrm{Al} \mathrm{2p}$, contributing to the increase in pozzolanic reactivity of FA. The performance of $\mathrm{CPB}$ samples prepared by wet-ground FA was then optimized. This was reflected by the acceleration in the sample setting and increase in the strength development. The compressive strength of the CPB samples prepared by wet-ground FA for $120 \mathrm{~min}$ was increased by around $40 \%$ after curing for $28 \mathrm{~d}$ compared with the control samples.
\end{abstract}

\section{Introduction}

Coal is the most abundant natural mineral resources on the earth, and it is also one of the main energy sources used by all countries [1-3]. One of the main uses of coal is to burn coal to generate electricity, which accounted for $72 \%$ of China's total power generation in 2015 [2]. Fly ash (FA) is the solid waste produced by coal-fired power plants [4-6]. It is the fine ash collected from the flue gas of coal combustion. FA can cause great harm to ecological environment and human health $[7,8]$. On the one hand, a large number of FA particles collected by electrostatic precipitators are stored in the open air, occupying a large amount of land. On the other hand, the FA contains $\mathrm{V}, \mathrm{Cr}, \mathrm{Ni}, \mathrm{Cd}, \mathrm{Pb}, \mathrm{As}, \mathrm{Zn}, \mathrm{Mo}$ and $\mathrm{Cu}$ and other heavy metals, which could cause serious pollution to the land, water, and air environment and then endangers human health [9-11]. Besides, fine FA particles are difficult to be captured by the dust collector and directly discharged into the atmosphere, becoming one of the main sources of atmospheric pollution. The fine FA submicron particles have a large concentration and usually contain a large number of toxic metal substances, which stay in the atmosphere for a long time. Once inhaled by the human body, it can penetrate deeply into the human alveoli, causing serious harm to human health. As a result, resource utilization of FA could alleviate its harm to environment and human body and balance the relationship between resources and environment.

FA has a wide range of applications. At present, its main technologies include manufacturing building materials (including cement [12], concrete [13], geopolymer [14, 15], road materials $[16,17]$, and engineering backfill materials $[18,19]$, soil improvement [20], synthesis of porous materials [21, 22], and extraction of valuable metals [23]. Considering the potential pozzolanic reactivity of FA, utilization of fly ash as pozzolanic material to replace part of cement has been proved to be an efficient way of FA disposal [24]. The addition of FA could modify the rheological properties of the fresh slurry due to the "ball effect" resulting from the spherical shape of the fly ash particles [25]. Besides, the finer particles of FA can fill the voids among cement grains and then increase the packing density and mechanical strength 
[26]. Durability of FA cement pastes and mortars in aggressive conditions has also been reported. The resistance of high volume FA cement pastes and mortars has been monitored when attacked by $\mathrm{HCl}, \mathrm{Na}_{2} \mathrm{SO}_{4}$ solution, and sea water [24]. The FA cement binder showed satisfactory resistance to the aggressive solutions comparing to a commercially available sulfate resistant cement reference [24].

Although some benefits from the utilization of FA as cement additives have been reported, some negative effects, such as delay of the setting time, have also been reported resulting from the poor reactivity of FA [27, 28], although the influence of FA is highly dependent on its characteristics. As reported by Zeng et al. [27], the FA reaction extent is still at a low level even after three months. Besides, negative effect of FA on the strength development (especially at early ages) and durability of FA cement was also reported. Obvious reduction in the compressive strength before $28 \mathrm{~d}$ was noticed even with low FA replacement [29]. The mechanical and physical properties of mortars with and without fly ash addition were investigated after being attacked by $\mathrm{NaCl}$ and $\mathrm{MgSO}_{4}$ solutions by Yildirim and Sümer [30]. The results indicated that the increase in the FA content seemed to have a negative effect on the mortar specimens. For example, flexural and compressive strength of 20\% FA replaced mortar specimens cured in water, $\mathrm{NaCl}$ and $\mathrm{MgSO}_{4}$ solutions were higher compared with 50\% FA replaced the mortar specimens. For this regard, the replacement level of FA in concrete is typically limited in the range of $15-25 \%$ [31], which restricts the large scale utilization of FA. Therefore, it is generally believed that reducing the particle size of fly ash and improving the reactivity can promote the recycling of FA in cementitious materials.

Cemented paste backfill (CPB) is one of the strategies for the comprehensive utilization of industrial wastes [32]. During the process of $\mathrm{CPB}$, ordinary Portland cement (OPC) is the main cementitious materials, accounting for approximately $70 \%$ of the total cost of CPB [33]. The high cost of OPC clearly increases the total cost of mine production. On the other hand, OPC production is considered as an energy-intensive process with the large power consumption, resulting in the emission of large amount of $\mathrm{CO}_{2}$, which accounts for approximately $5-8 \%$ of the total $\mathrm{CO}_{2}$ emissions in the world $[34,35]$. Thus, it is necessary to prepare alternative binders with lower cost and $\mathrm{CO}_{2}$ emissions. Using supplementary cementitious materials seems to be one of the commonly used methods to lower the OPC utilization.

FA has been reported to be used in CPB. Liu et al. [36] studied the consequences of temperature on the physical and mechanical properties and microstructure of CGFB when using FA in $\mathrm{CPB}$ at a mass ratio of cement: coal gangue: fly ash of $1: 2: 5$. The increase of curing temperature promotes the early appearance of pozzolanic effect of fly ash. Higher curing temperatures made early compressive strength of $\mathrm{CPB}$ specimens increase, but later compressive strength decreased due to the decrease of the bonding of the internal structure due to the thermal damage [36]. Cavusoglu et al. [18] studied the effect of sodium silicate as an accelerator on early age mechanical and microstructure properties of cemented coal fly ash backfill (CCB). Sodium silicate was found to accelerate setting time and strength of CCB. In another study [37], the effect of water-reducing admixtures on properties of CCB was studied. Admixtures enhanced short- and long-term CCB strengths up to $33 \%$ and decreased the porosity. However, to the best of our knowledge, there are few studies focusing on the effect of pretreated FA on the properties of CPB samples. Mechanical refinement is one of the most effective treatment technologies for industrial solid waste disposal [38]. After mechanical activation, the reactivity of the mineral particles is increased due to the physical and chemical alterations [39]. Mechanical activation could decrease the particle size and increase the specific surface area and then increase the contact area between the reactive substances [40]. Therefore, in the present work, wet-grinding was used to pretreat FA with the aim of increase its pozzolanic reactivity. The effect of wetgrinding was evaluated via physical structure, mineralogical modification, and dissolution behavior. The wet-ground FA was used in $\mathrm{CPB}$. The reaction kinetic, setting time, compressive strength development, and pore structure of the $\mathrm{CPB}$ samples were then investigated.

\section{Materials and Methods}

2.1. Materials. Two types of fly ash (FA) studied in the present work were collected from Liaoning and Hebei, China, respectively. The received FA was dried in an oven under $105^{\circ} \mathrm{C}$ for $24 \mathrm{~h}$. Ordinary Portland cement (42.5R) produced by CR Cement Co. Ltd was used in the present work. The chemical compositions of the cement are listed in Table 1, measured via X-ray fluorescence (XRF). The specific surface area of the cement was $334 \mathrm{~m}^{2} / \mathrm{kg}$, measured using the Blaine method.

\subsection{Experiments}

2.2.1. Mechanical Treatment of Fly Ash. The mechanical treatment of FA was conducted using a wet-grinding method by a vertical stirred mill. Zirconia ball was used as grinding medium with a weight ratio of $10 \mathrm{~mm}: 8 \mathrm{~mm}$ : $6 \mathrm{~mm}: 2 \mathrm{~mm}=1: 4: 6: 2$. Zirconia balls, FA, polycarboxylate-based superplasticizers (PCE), and water were poured into the mill after separately weighted with the ratio of water $/ \mathrm{FA}=0.5, \mathrm{FA} /$ grinding media $=0.5, \mathrm{PCE} / \mathrm{FA}=0.3 \%$. The FA was then ground for 10, 30, 60, and 120 min using the motor speed of $450 \mathrm{rpm}$. After reaching the designed grinding duration, the balls were separated. The FA slurry was then used for the following tests with no need to be dried. FA was wet-milled for 10, 30, 60, and $120 \mathrm{~min}$ and was labeled as FA10, FA30, FA60, and FA120, respectively. The raw FA without mechanical treatment was named as FA0.

2.2.2. Dissolution Behavior. The ground dried FA samples were placed into $\mathrm{NaOH}$ solution $(0.10 \mathrm{~mol} / \mathrm{L})$ at a liquid/ solid ratio of $100 \mathrm{ml} / \mathrm{g}$ and stirred for 36 hours. The solution was then filtered via a preweighed $0.2 \mu \mathrm{m}$ nylon syringe filter 
Table 1: Chemical compositions of the cement (wt.\%).

\begin{tabular}{lccccccccc}
\hline $\mathrm{CaO}$ & $\mathrm{Al}_{2} \mathrm{O}_{3}$ & $\mathrm{SiO}_{2}$ & $\mathrm{MgO}$ & $\mathrm{Fe}_{\mathrm{x}} \mathrm{O}$ & $\mathrm{Na}_{2} \mathrm{O}$ & $\mathrm{K}_{2} \mathrm{O}$ & $\mathrm{SO}_{3}$ & $\mathrm{MnO}_{2}$ & $\mathrm{P}_{2} \mathrm{O}_{5}$ \\
\hline 58.23 & 6.84 & 25.65 & 5.29 & 2.77 & 0.19 & 0.16 & 0.79 & 0.05 & 0.03 \\
\hline
\end{tabular}

at designed time intervals. The dissolved tailings can be calculated as follows:

$$
\text { dissolved mass percentage }=\frac{1-m}{1} \times 100 \%,
$$

where $m$ is the weight of undissolved solid particles.

2.2.3. Pozzolanic Reaction. The method used in [41, 42] was conducted to investigate the pozzolanic reactivity of FA. First, FA, limestone, and portlandite were dry-mixed before $\mathrm{NaOH}$ solution being poured into the mixture. The $\mathrm{H}_{2} \mathrm{O}$ /binder ratio of 0.5 was used in this work. After mixing for $2 \mathrm{~min}$, the paste was poured into $20 \mathrm{~mL}$ centrifuge tubes and cured at $20^{\circ} \mathrm{C}$ until the targeted ages. Table 2 shows the mix proportion.

\subsubsection{Utilization of Wet-Ground Fly Ash in Cemented Paste} Backfill. To prepare the CPB samples, OPC was replaced by FA of $40 \mathrm{wt} \%$. The OPC, FA, and tailings were dry-mixed for 1 min before adding water. In the present work, the binder/ tailings ratio was $1 / 6$, and the solid content was $72 \mathrm{wt} \%$. The mixture was then poured into cylindrical plastic molds with a dimension of $50 \mathrm{~mm}$ in diameter and $100 \mathrm{~mm}$ in height after blended for another $2 \mathrm{~min}$. The samples were then sealed and cured at $20^{\circ} \mathrm{C} / 95 \%$ R.H. for one day. After that, the samples were demolded and cured at $20^{\circ} \mathrm{C} / 95 \%$ R.H. until designated curing ages. To study the reaction kinetic, the paste without tailings addition was used, and similar preparation procedure like the preparation of CPB samples illustrated above was conducted.

2.3. Characterization Methods. The particle size distribution of FA was tested via a Malvern Mastersizer 2000 in a range from $0.02 \mu \mathrm{m}$ to $2000 \mu \mathrm{m}$ using alcohol as dispersion medium.

X-ray diffractometry (XRD) was used to identify the phase assembles of the samples via a Shimadzu XRD-7000. For the hydrated samples, the hardened samples were crushed to $<74 \mu \mathrm{m}$. After that, they were rinsed with isopropanol (A.R., 99.7\%) and stirred for $1 \mathrm{~h}$ for the reaction stopping. Next, they were filtered and used for XRD analysis after dried for $24 \mathrm{~h}$ under vacuum condition. The samples were scanned in the range between $5^{\circ}$ and $50^{\circ}$ with a rate of $2^{\circ}$ per minute.

Thermogravimetric tests were carried out using a thermogravimetry (TG)/differential thermal analysis system (STA409PC). The heating temperature ranged from room temperature to $1000^{\circ} \mathrm{C}$ using a heating rate of $15^{\circ} \mathrm{C} / \mathrm{min}$. The tests were conducted under an atmosphere of high-purity nitrogen.

Microstructure of the samples was observed with a scanning electron microscopy system (Zeiss Gemini 300). For the unhydrated FA samples, FA particles were uniformly
TABLe 2: Mix proportion of the system for pozzolanic reactivity tests (wt.\%).

\begin{tabular}{lcccc}
\hline FA & Portlandite & Limestone & $\mathrm{NaOH}$ & $\mathrm{H}_{2} \mathrm{O} /$ binder \\
\hline 50 & 38 & 10 & 2 & 0.5 \\
\hline
\end{tabular}

dispersed on a double-sided adhesive tape and coated with a gold film to increase electrical conductivity. The microscope was operated in the high vacuum mode, with an accelerating voltage of $20 \mathrm{kV}$.

$\mathrm{X}$-ray photoelectron spectroscopy (XPS) analysis was conducted using a Thermo ESCALAB 250XI XPS system with a monochromatic $\mathrm{Al} \mathrm{K} \alpha \mathrm{X}$-ray beam $(h v=1486.68 \mathrm{eV})$ having a diameter of $500 \mu \mathrm{m}$.

A TAM Air isothermal calorimeter (TA/TAM AIR-8) was used to test the heat release during the hydration. The method for slurry preparation was similar to that illustrated in Section 2.2. After preparation, the slurry was immediately transferred to the isothermal calorimeter for testing. The recording duration was about $72 \mathrm{~h}$ at $20^{\circ} \mathrm{C}$.

The setting time of the composites was measured by the depth of penetration of the Vicat needle into the composites following the method in [43]. The compressive strength of the composites was measured using the standard method ASTM C39. Before testing, the top and bottom surfaces of the cylindrical samples were ground flat for good contact with the probe. The ultimate data was derived from the average values of at least three samples.

The pore structure was analyzed by mercury intrusion porosimetry (MIP, Autopore IV 9500). Crushed samples with a size of 1-2 mm were used. Before testing, the crushed samples were rinsed with isopropanol (A.R., 99.7\%) as illustrated previously.

A Brookfield RSR-SST rheometer was used to measure the rheological parameters (i.e., yield stress and plastic viscosity) of fresh $\mathrm{CPB}$ mixtures. The rotator was a fourbladed vane type with a diameter and length of 20 and $40 \mathrm{~mm}$, respectively. Rheological testing was performed after pouring the prepared fresh $\mathrm{CPB}$ into the test cup following the rheology protocol shown in Figure 1. First, the fresh CPB slurry was homogenized via a preshear phase at $100 \mathrm{~s}^{-1}$ lasting $60 \mathrm{~s}$. This was followed by a ramp-up $\left(0 \longrightarrow 100 \mathrm{~s}^{-1}\right)$ and ramp-down $\left(100 \longrightarrow 0 \mathrm{~s}^{-1}\right)$ process conducted within $120 \mathrm{~s}$ after resting for $15 \mathrm{~s}$. The data were collected from the descending stage.

\section{Results and Discussion}

3.1. Characterization of the Raw Fly Ash. The chemical composition of the two studied FA is shown in Table 3. It was clearly that the main compositions of both the two FA were $\mathrm{Al}_{2} \mathrm{O}_{3}$ and $\mathrm{SiO}_{2}$, accounting for more than $80 \%$ of the total content. This was in line with previous reports [44, 45]. 


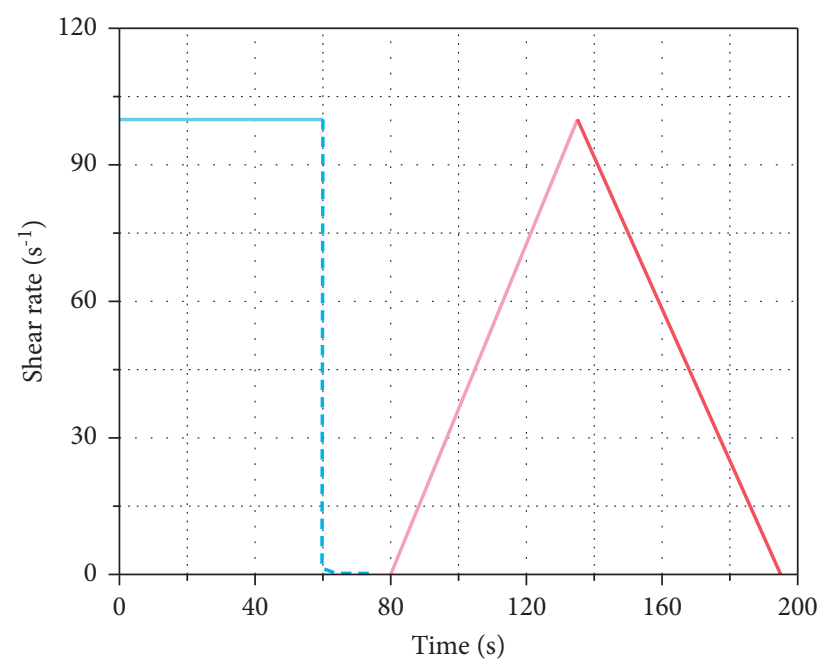

FIgURE 1: Schematic representation of the applied rheology protocol.

However, FA1 clearly contained more $\mathrm{Al}_{2} \mathrm{O}_{3}$ compared with FA2, which contained higher amount of $\mathrm{SiO}_{2}$. More $\mathrm{CaO}$ was detected in FA1, while FA1 contained more MgO. The differences in the chemical composition could lead to the various behavior when being used to prepared binders.

Figure 2 shows the microstructure of the two FA. The shape of FA1 was irregular and mainly consisted of spongy hollow vitreous particles with loose structure as shown in Figure 2(a). FA2 was dominated by spherical particles. The shape of the particles was reported to highly influence the rheological properties of the slurry.

\subsection{Mechanical Transformation of Fly Ash}

3.2.1. Particle Size Distribution. The particle size distribution of FA before and after mechanical activated for $10 \mathrm{~min}$, $30 \mathrm{~min}, 60 \mathrm{~min}$, and $120 \mathrm{~min}$ is presented in Figure 3. Wetgrinding strongly modified the particle size distribution. As shown from Figures 3(a) and 3(b), only one main peak was noticed in the particle size distribution curves of both FA1 and FA2, no matter the grinding duration. This was different from our previous work about the particle size distribution of mechanical activated coal gangue, where a typical bimodal distribution was observed [38]. Besides, the peak of the particle size distribution got narrower with the increase of the grinding duration, indicating a more uniform particles [46]. Figures 3(c) and 3(d) shows that the d10, d50, and d90 values of the two FA decreased with the increase of grinding duration. These values did not show significant changes after grinding for $60 \mathrm{~min}$. At the same time, the specific surface area (SSA) obtained from the particle size analysis data gradually increased with the grinding duration: increase from $1137 \mathrm{~m}^{2} / \mathrm{g}$ to $2614 \mathrm{~m}^{2} / \mathrm{g}$ for $\mathrm{FA} 1$, and $1331 \mathrm{~m}^{2} / \mathrm{g}$ to $2608 \mathrm{~m}^{2} / \mathrm{g}$ for FA2, respectively.

3.2.2. X-Ray Diffraction and X-Ray Photoelectron Spectroscopy Analysis. The mineralogical structure changes of FA resulting from wet-grinding are shown in Figure 4.
The XRD results showed that the main crystalline phases were mullite and quartz. No new phases were identified after wet-grinding, even after grinding for $120 \mathrm{~min}$. However, the intensity for quartz and mullite decreased after wet-grinding. This was mainly caused by the sheer force and friction between grains and grinding media, leading to plastic deformation of the particles and collapse of the crystalline structure [47]. The reason why FA presented lower reactivity under attacking of alkaline species was the high crystalline content; thus, the reduction of quartz and mullite intensity could then favor the enhancement of the reactivity of FA.

$\mathrm{X}$-ray photoelectron spectroscopy (XPS) analysis was used to investigate the surface characteristics of FA after wetgrinding, and the results are shown in Figure 5. It was found that the binding energy of both $\mathrm{Si} 2 \mathrm{p}$ and $\mathrm{Al} 2 \mathrm{p}$ in the two FA decreased with the grinding time. A similar phenomenon was reported elsewhere $[46,47]$. The reduction in the binding energy of $\mathrm{Si}$ and $\mathrm{Al}$ is beneficial to the increase in the pozzolanic reactivity as it witnessed an easy breakage of chemical bonds during reaction [46].

\subsubsection{Dissolution Behavior of the Mechanically Treated Fly} Ash in Alkaline Solution. The reaction of FA under alkali activation started from the dissolution of solid particles, which is considered as the crucial procedure for the conversion of the solid particles into available source material [48]. The dissolution behavior also controlled the reaction and properties of OPC/FA composites [38]. Thus, it is necessary to make sense of the dissolution behavior of the FA after mechanical activation. The dissolution behavior of FA under alkaline environment was shown in Figure 6. The testing results showed a parabolic trend, where the dissolved FA increased with the dissolution time until around $20 \mathrm{~h}$ at far-from-equilibrium conditions. After that, the dissolution reached equilibrium with only minor amounts dissolved. This was in line with previous reports about the dissolution behavior of other mineral particles $[48,49]$. One difference was that more time was needed to reach dissolution equilibrium in this experiment. This could be attributed to the 
TABle 3: Chemical compositions of the raw FA.

\begin{tabular}{|c|c|c|c|c|c|c|c|c|c|c|c|c|c|c|}
\hline Raw materials & $\mathrm{CaO}$ & $\mathrm{Al}_{2} \mathrm{O}_{3}$ & $\mathrm{SiO}_{2}$ & $\mathrm{MgO}$ & $\mathrm{Fe}_{\mathrm{x}} \mathrm{O}$ & $\mathrm{Na}_{2} \mathrm{O}$ & $\mathrm{K}_{2} \mathrm{O}$ & $\mathrm{SO}_{3}$ & $\mathrm{MnO}_{2}$ & $\mathrm{P}_{2} \mathrm{O}_{5}$ & $\mathrm{SrO}$ & $\mathrm{TiO}_{2}$ & $\mathrm{ZrO}_{2}$ & LOI \\
\hline FA1 & 3.82 & 47.93 & 38.73 & 0.31 & 5.91 & 0.25 & 0.26 & 0.33 & 0.26 & 0.64 & 0.03 & 1.5 & 0.03 & 0.92 \\
\hline FA2 & 1.55 & 25.52 & 62.31 & 1.4 & 6.52 & 0.47 & 0.54 & 0.27 & 0.31 & 0.15 & 0.02 & 0.85 & 0.09 & 1.26 \\
\hline
\end{tabular}

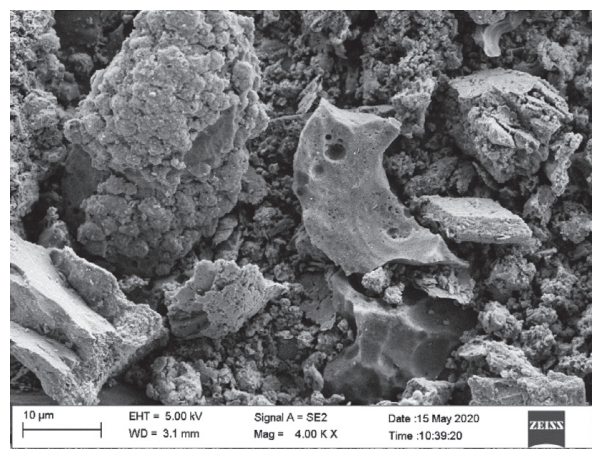

(a)

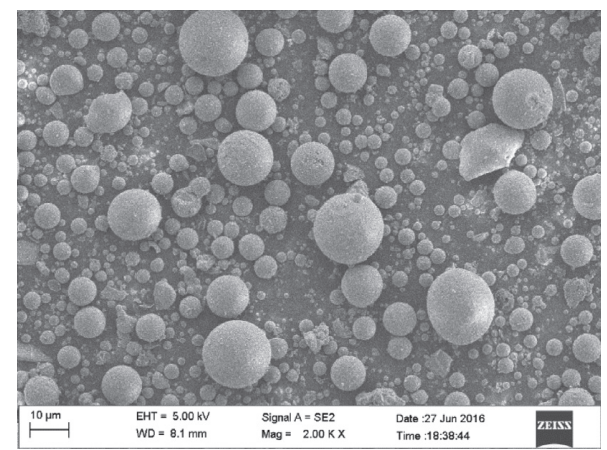

(b)

FIgURE 2: Microstructure of the FA: (a) FA1 and (b) FA2.

lower reactivity of FA compared with the materials used elsewhere, such as calcined clay [48]. Both FA1 and FA2 showed an increased trend in the dissolution rate after wetgrinding. The faster dissolution confirms the enhanced reactivity of FA after wet-grinding. On the other hand, FA2 clearly showed higher dissolution rate than that of FA1.

3.2.4. Pozzolanic Performance. Figure 7 shows the calorimetry test results of the pozzolanic test. The heat release during the pozzolanic was caused by the dissolution of FA in alkaline environment with the formation of hydration gels. The heat flow curves, as shown in Figures 7(a) and 7(b), were different from that of the cement-based binders, mainly resulting from the low reaction rate during the alkali activation process. Generally, wet-grinding increased the heat release rate in both $\mathrm{FA} 1$ and $\mathrm{FA} 2$, indicating that the pozzolanic reactivity increased with the wet-grinding time. This was in line with the dissolution tests' results, which showed that the dissolved FA increased with the mechanical grinding duration. Besides, FA2 presented higher heat flow rate than that of the FA1, suggesting a higher pozzolanic reactivity.

Figures 7(c) and 7(d) show the total heat flow during the pozzolanic reaction, and the cumulative heat flow increased with the wet-grinding time. The raw FA presented lower reactivity and witnessed a low total heat release, reaching around only $23.19 \mathrm{~J} / \mathrm{g}$ and $39.04 \mathrm{~J} / \mathrm{g}$ for FA1 and FA2, respectively. After wet-grinding for $120 \mathrm{~min}$, the total heat release increased dramatically, reaching $76.77 \mathrm{~J} / \mathrm{g}$ and $117.51 \mathrm{~J} / \mathrm{g}$ for FA1 and FA2, respectively. This directly proves the effect of the wetmilling process, where the pozzolanic reactivity of FA was enhanced after wet-grinding. This could lead to more FA dissolving (Figure 7) and taking part in the pozzolanic reaction, contributing to more hydration heat release.
Thermogravimetry (TG) analysis was used to investigate the constituent parts of the hydration products of the pozzolanic reaction, and the results are shown in Figure 8. The peak located between $50^{\circ} \mathrm{C}$ and $200^{\circ} \mathrm{C}$ was caused by the decomposition of the C-S-H. This implied that mechanical grinding did not modify the phase assembles of the hydration products. Besides, it was clear that the intensity of this peak increased with the grinding duration. This phenomenon suggested that more FA participated into the pozzolanic reaction, in line with the results of dissolution tests. On the other hand, FA2 presented higher intensity of this peak than that of the FA1, indicating that FA2 showed higher pozzolanic reactivity than FA1.

\subsection{Utilization of the Mechanically Treated Fly Ash in Cemented Paste Backfill}

3.3.1. Reaction Kinetics of the Pastes. The early reaction kinetics of the binders used for CPB was studied by isothermal calorimetric analysis. Figure 9 shows the calorimetry test results of the paste binders of FA-OPC used for cemented paste backfill. Generally, four stages were noticed in all the heat flow rate curves (Figures 9(a) and 9(b)), that is, the initial, induction, acceleration, and deceleration stages. Wet-grinding clearly promoted the binders hydration, which was reflected by shortening the induction period and the heat flow rate at the main peak. Table 4 summarizes the kinetic data for the all the binders. For FA1, the ending time of the induction period $\left(t_{1}\right)$ decreased from $8.22 \mathrm{~h}$ to $7.68 \mathrm{~h}$, $7.32 \mathrm{~h}, 7.04 \mathrm{~h}$, and $6.86 \mathrm{~h}$ when wet-grinding for $10 \mathrm{~min}$, $30 \mathrm{~min}, 60 \mathrm{~min}$, and $120 \mathrm{~min}$, respectively. This was accompanied by the advance of the occurrence of the main hydration peak, from $19.29 \mathrm{~h}$ to $17.93 \mathrm{~h}, 16.84 \mathrm{~h}, 15.76 \mathrm{~h}$, and $14.58 \mathrm{~h}$, after wet-grinding for $10 \mathrm{~min}, 30 \mathrm{~min}, 60 \mathrm{~min}$, and $120 \mathrm{~min}$, respectively. At the same time, the maximum heat 


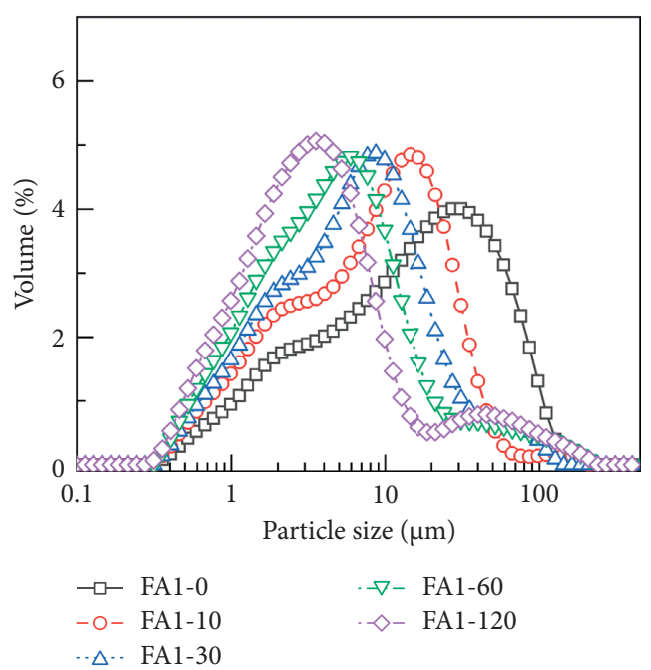

(a)

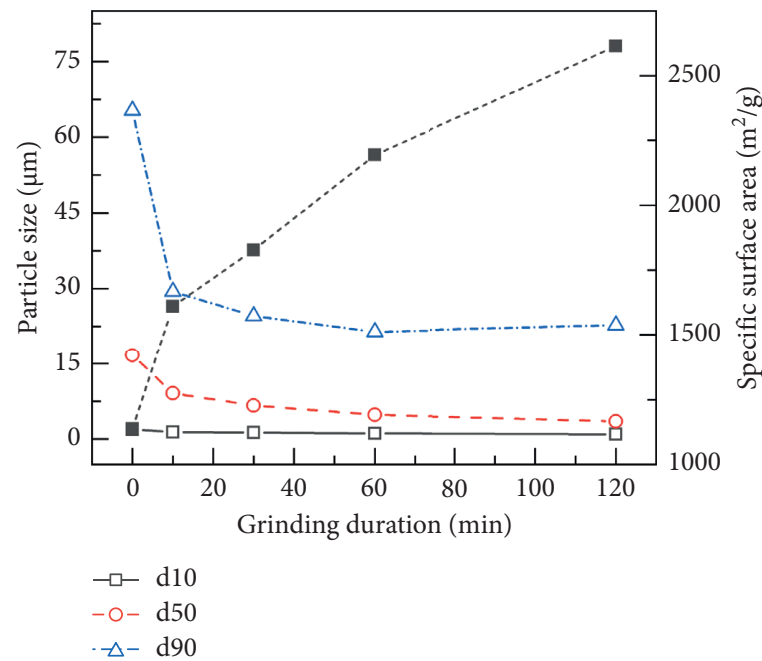

(c)

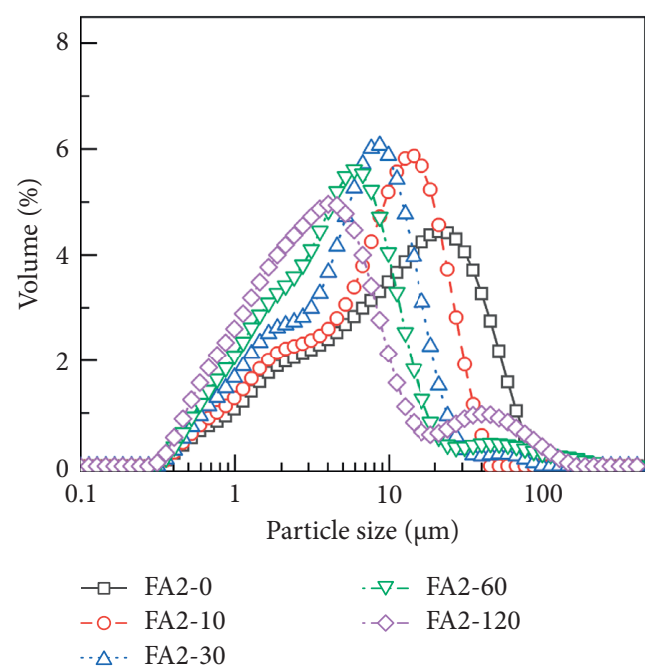

(b)

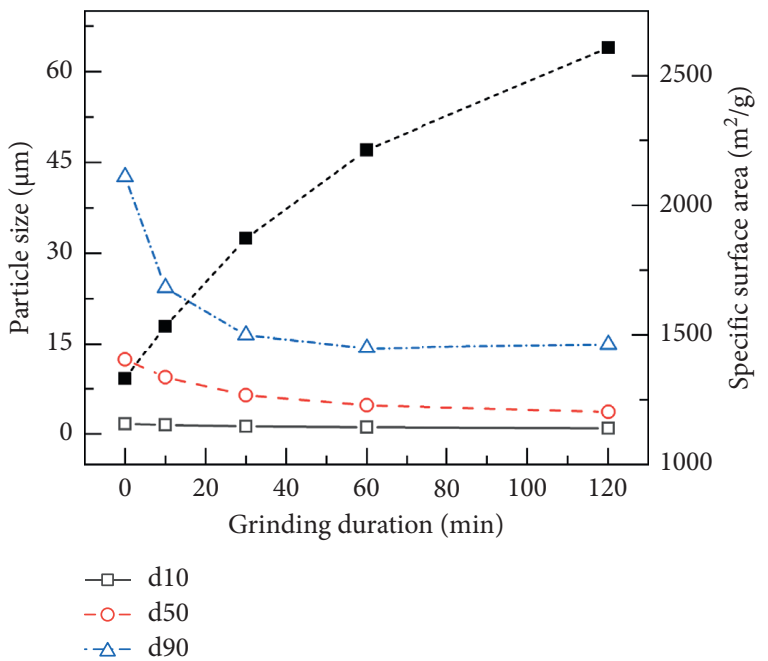

(d)

FIgURE 3: Particle size distribution of (a) FA1 and (b) FA2; characteristic particle parameters (c) FA1 and (d) FA2.

release rate increased by around $10.89 \%, 12.50 \%, 5.56 \%$, and 6.02\%, for FA1-10, FA1-30, FA1-60, and FA1-120, respectively. All these suggested that the acceleration of cement hydration. Similar trend happens in the FA2 samples. Figures 9(c) and 9(d) show the cumulative heat release during the binders' hydration for $72 \mathrm{~h}$. It was clear that mechanical grinding increased the total heat release in both FA1 and FA2, as listed in Table 4.

The acceleration was attributed to two factors. For one thing, the pozzolanic reactivity of FA was increased as illustrated in Section 3.2.4 after mechanical activation. More FA would participate into the reaction under the activation of portlandite from the cement hydration. For another, the fine particles of FA could act as crystal nucleus to reduce the induction period and accelerate the hydration process, which is known as the "nucleus effect" [50]. This was consistent with previous reports, which indicated that the application of superfine additives could accelerate the cement hydration, including synthesized C-S-H [51-53], ferrihydrite nanoparticle [54], and $\mathrm{SiO}_{2}, \mathrm{TiO}_{2}$, and $\mathrm{Fe}_{2} \mathrm{O}_{3}$ nanoparticles [55]. The "nucleus effect" clearly increased with the increase of grinding duration as more fine FA particles would be produced under the mechanical milling, as shown in Figure 3. This led to a more obvious effect on the acceleration of the hydration process.

3.3.2. Rheological Properties. Rheological properties were the important performance of fresh CPB [56], which affected the pumping efficiency and mine production [57]. Thus, the rheological properties of the fresh cemented paste backfill were tested, and the results are shown in Figure 10. As shown in Figure 10(a), the yield stress increased with the wet-grinding duration, suggesting that higher threshold amount of stress is required to initiate flow. Comparing with the controlled samples, after wet-grinding for $10 \mathrm{~min}, 30 \mathrm{~min}, 60 \mathrm{~min}$, and $120 \mathrm{~min}$, the yield stress increased by $48.01 \%, 38.94 \%, 26.91 \%$, and $4.49 \%$, respectively. This negative effect of mechanical 

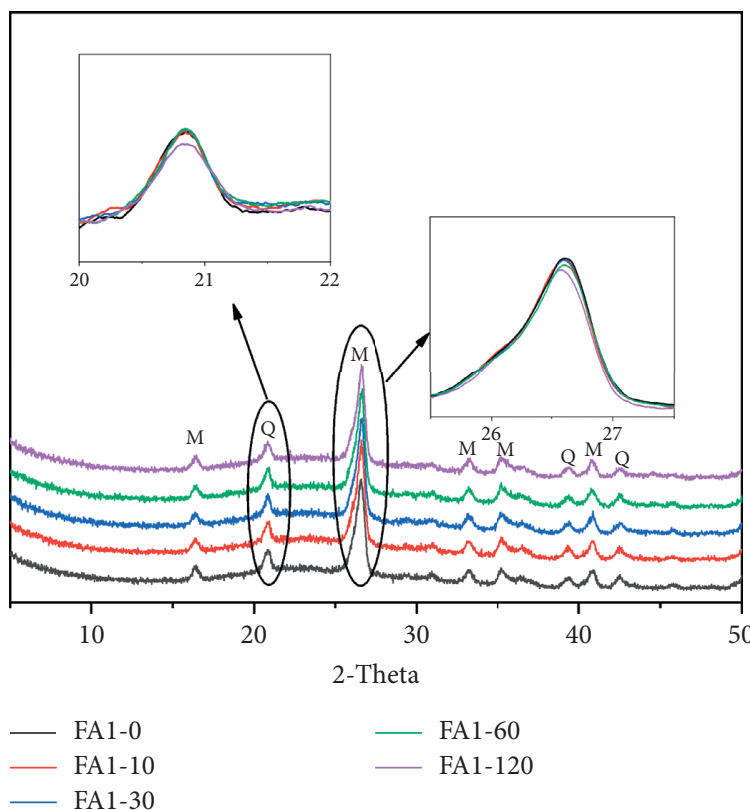

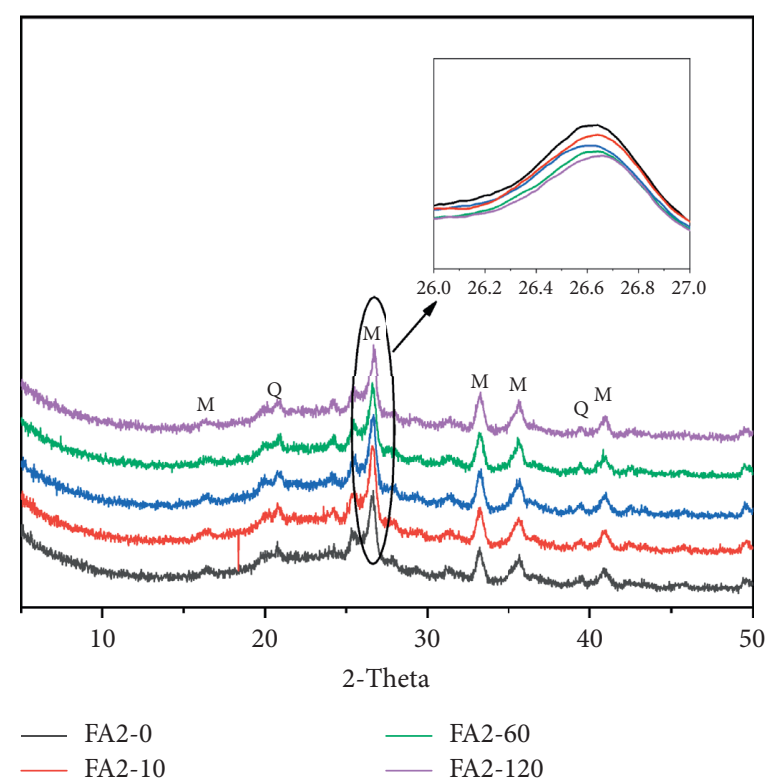

(b)

Figure 4: Phase assembles of FA: (a) FA1 and (b) FA2 (M: mullite; Q: quartz).

grinding on the yield stress can be attributed to the combined effect of the following mechanisms: the coupling effect of particle packing density and specific surface area is the key to the yield stress and plastic viscosity of $\mathrm{CPB}$. On the one hand, the increase of the packing density will increase the extra water amount to form the water film; on the other hand, the increase of the specific surface area will decrease the thickness of the water film. Therefore, although the packing density of the granular system increases due to the filling effect of fine grains, the specific surface area also increases, and the net effect of these two factors leads to the phenomenon in this paper; the pozzolanic reactivity was increased after mechanical activation, as shown in Section 3.2.4. This led to promoted hydration process with the formation of more hydration gels in a shorter time compared with the controlled sample, resulting in increased yield stress. This could be confirmed by the promoted hydration rate in the calorimetry test results, as shown in Figure 9. Indeed, an increase in hydration products and a reduction in free water enhances the interfrictional resistance of the particle assembly of the $\mathrm{CPB}$, which in turn increases the yield stress [58].

The flowability of the fresh CPB is shown in Figure 10(b), and it was clear that the flowability of both the samples prepared with FA1 and FA2 decreased with the grinding duration. For the samples with raw FA1 addition, the flowability of the fresh $\mathrm{CPB}$ was around $25.6 \mathrm{~cm}$. After wetgrinding for $10 \mathrm{~min}, 30 \mathrm{~min}, 60 \mathrm{~min}$, and $120 \mathrm{~min}$, the flowability decreased to about $23.7 \mathrm{~cm}, 22.1 \mathrm{~cm}, 20.2 \mathrm{~cm}$, and $18.2 \mathrm{~cm}$, respectively. The reduction in the flowability was caused by the increased yield stress, as shown in Figure 10(a). In general, to fulfill the requirement of transportation to stopes by pumping or self-flowing, the flowability of the fresh CPB slurry should be $19-27 \mathrm{~cm}$ [59]. The flowability of the slurry was slightly below the minimum requirement for $\mathrm{CPB}$ when adding $\mathrm{FA} 1$ after wet-ground for $120 \mathrm{~min}$.

As shown in Figure 2, FA2 was dominated by spherical particles. The "ball effect" of FA2 particles contributes to higher flowability. Although FA2 showed higher pozzolanic reactivity, which can form more hydration gels in a shorter time than FA1 and decrease the flowability, it is obvious this factor has a minor effect. Thus, the physical properties of FA showed a higher impact on the flowability of binders than the chemical properties.

3.3.3. Setting Time and Compressive Strength. The setting time and compressive strength, which determine the mining process and safety, are another two factors influencing the practical applications of the cementitious binders in $\mathrm{CPB}$ [60-62]. The initial setting time and compressive strength after curing for $28 \mathrm{~d}$ are shown in Figures 11(a) and 11(b). The CPB samples using raw FA1 and FA2 showed a relatively long initial setting time, reaching around $10.2 \mathrm{~h}$ and $8.1 \mathrm{~h}$, respectively (Figure 11(a)). Wet-grinding significantly promoted the initial setting of the СРB samples. The reduction of the initial setting time was approximately $39.2 \%$ and $33.3 \%$ when the FA was ground for $120 \mathrm{~h}$. This phenomenon was in line with the calorimetry test results, where the reaction was promoted by the wet-grinding, leading to faster formation of hydration gels. This would then promote the samples setting. FA2 showed faster setting than FA1, resulting from its higher pozzolanic reactivity, as illustrated in Section 3.2.4.

Figure 11(b) shows the compressive strength of the CPB samples after curing for $28 \mathrm{~d}$. The compressive strength of the $\mathrm{CPB}$ samples was low when using the raw FA, reaching around $0.87 \mathrm{MPa}$ and $0.98 \mathrm{MPa}$, respectively, after curing for $28 \mathrm{~d}$. This 


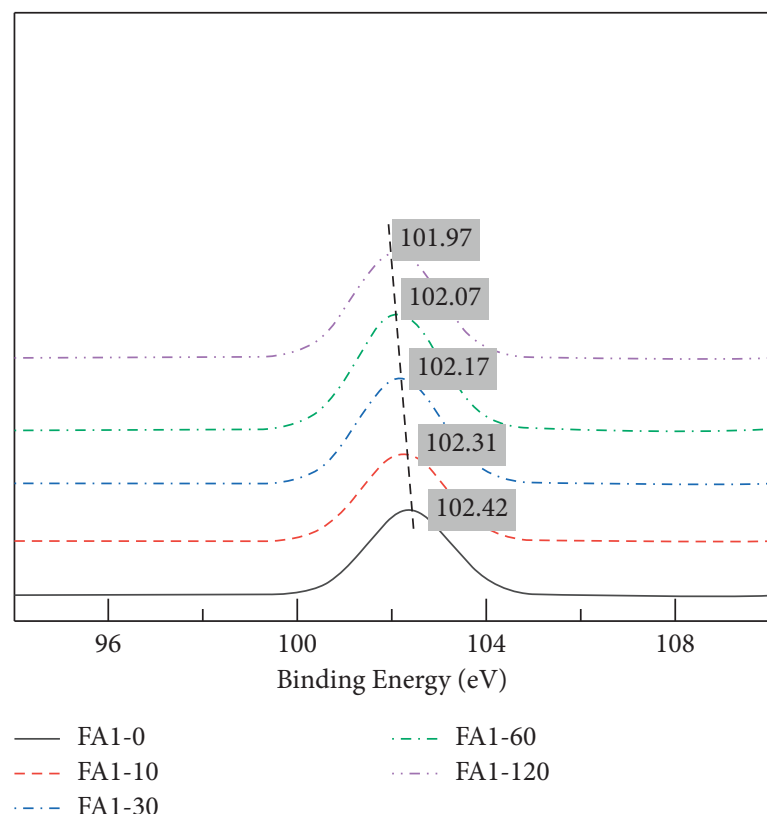

(a)

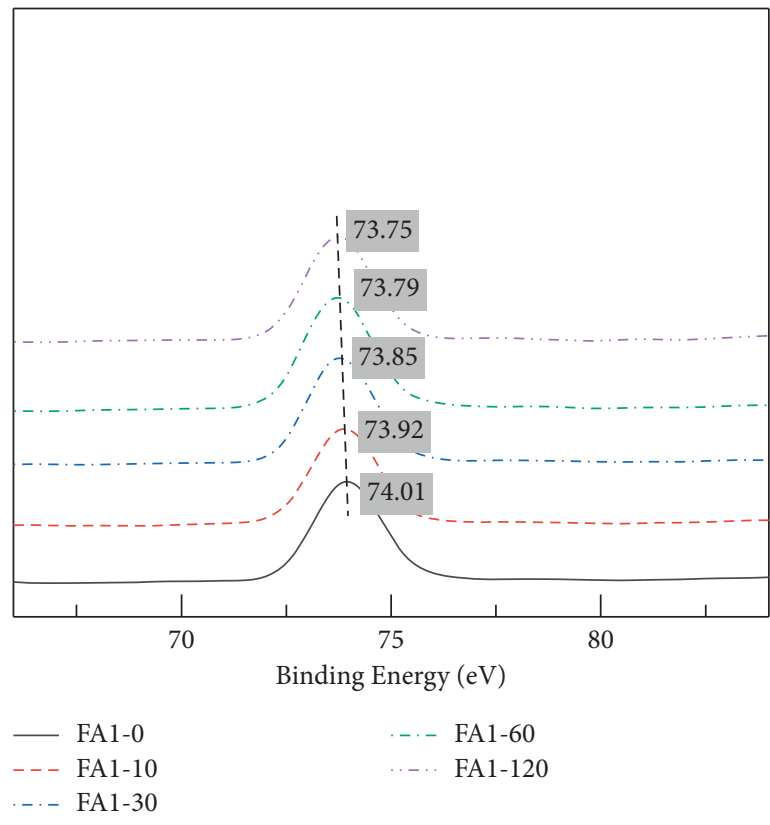

(c)

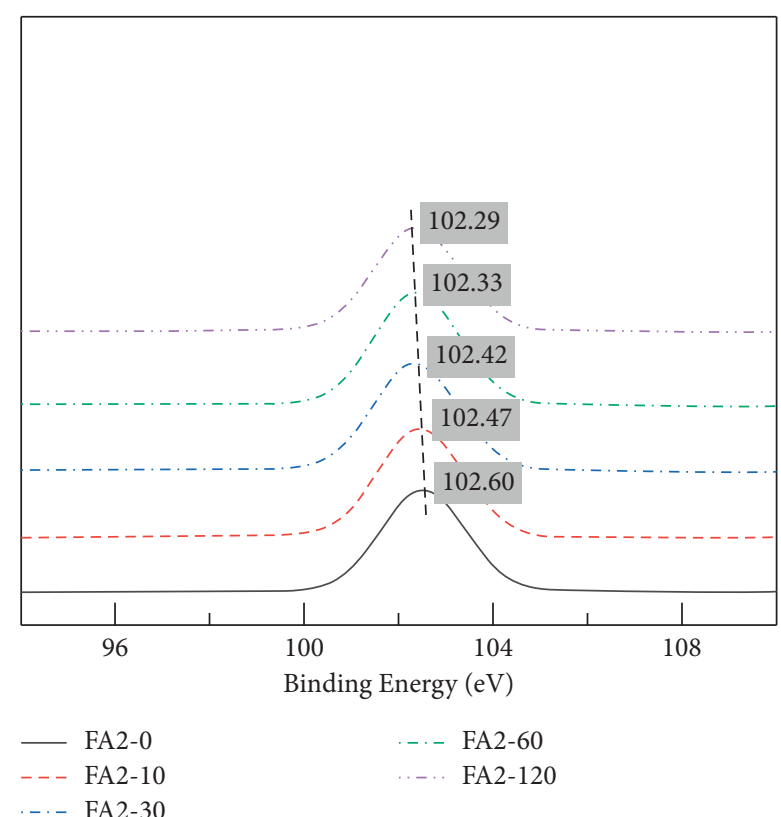

(b)

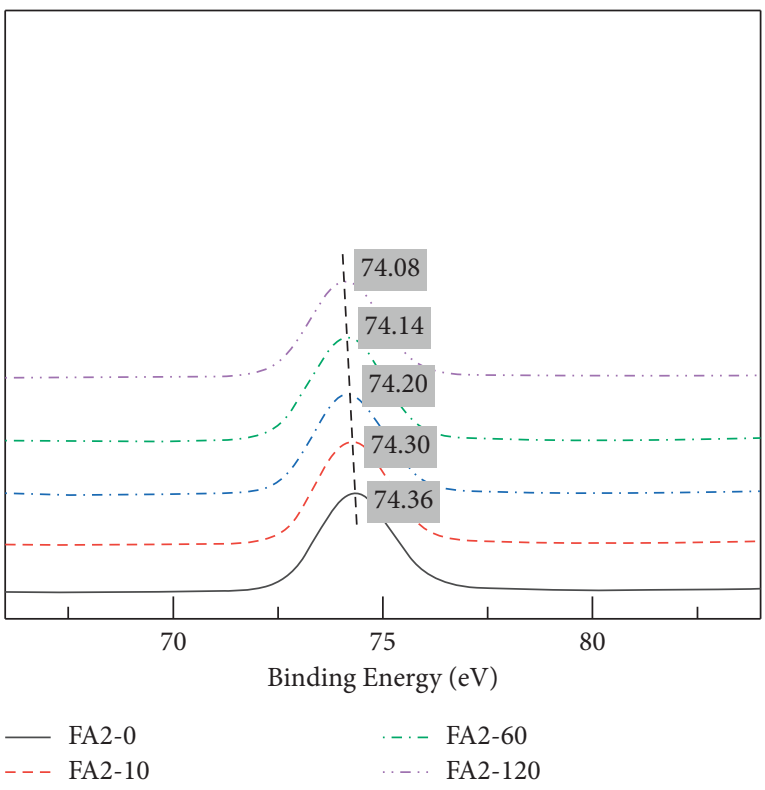

(d)

FIgURE 5: XPS analysis results: (a, b) Si 2p and (c, d) Al 2p.

was attributed to the relatively lower pozzolanic reactivity of the raw FA, in line with previous reports about the FA-doped cement [63]. After wet-grinding, the compressive strength increased with the grinding time, reaching around 1.21 MPa and $1.36 \mathrm{MPa}$ for FA1 and FA2, respectively, after grinding for $120 \mathrm{~min}$. As illustrated in Section 3.2.6, the pozzolanic reactivity increased after mechanical grinding, leading to more FA participating in the reaction. Besides, more fine particles were produced after grinding, which contributed to the reaction process due to the more "nucleation sites." Furthermore, the finer particle could fill the voids during the hardening of the cement, leading to more compact matrix. All these could favor the strength development of the samples. During the reaction of FA-cement, FA will dissolve under the alkali activation of portlandite. FA2 clearly showed higher dissolution rate, as shown in Figure 6. This will then contribute to the formation of more hydration gels, favoring the strength development.

3.3.4. Pore Structure. The pore structure of the hardened CPB samples after curing for $28 \mathrm{~d}$ is shown in Figure 12. According to a previous report [64], the pores in the 


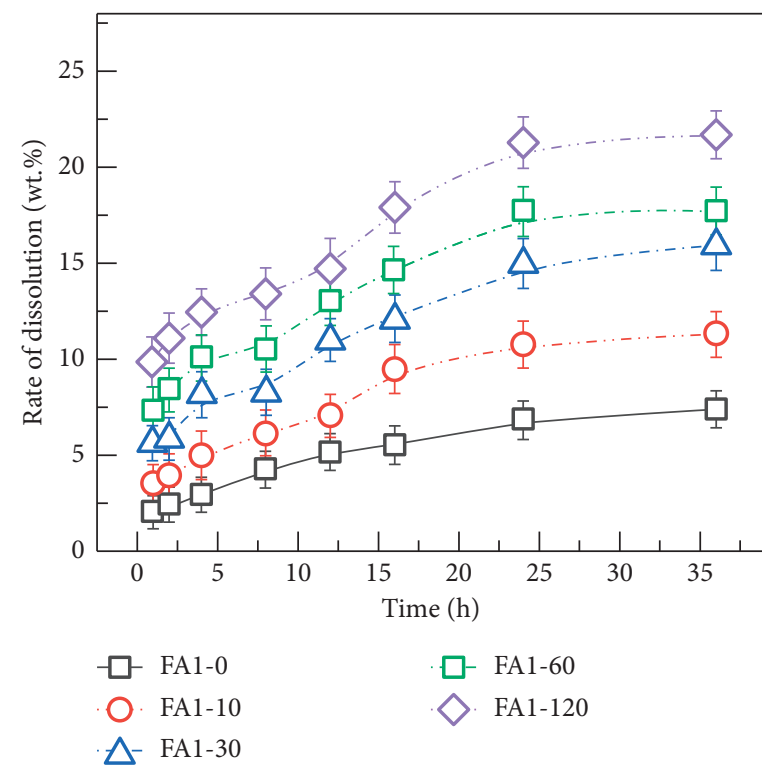

(a)

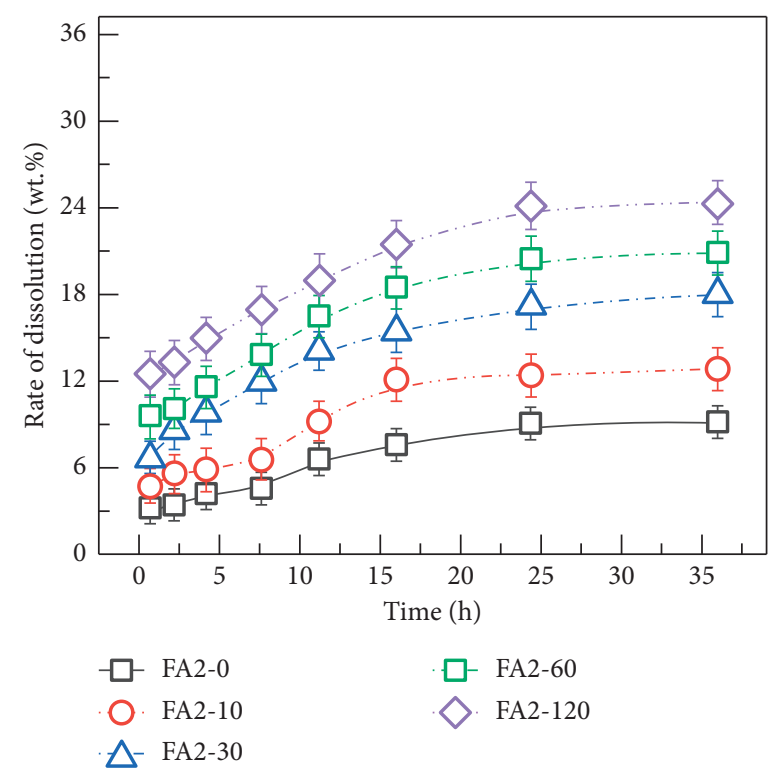

(b)

FIGURE 6: Dissolution characteristics of the fly ash: (a) FA1 and (b) FA2.

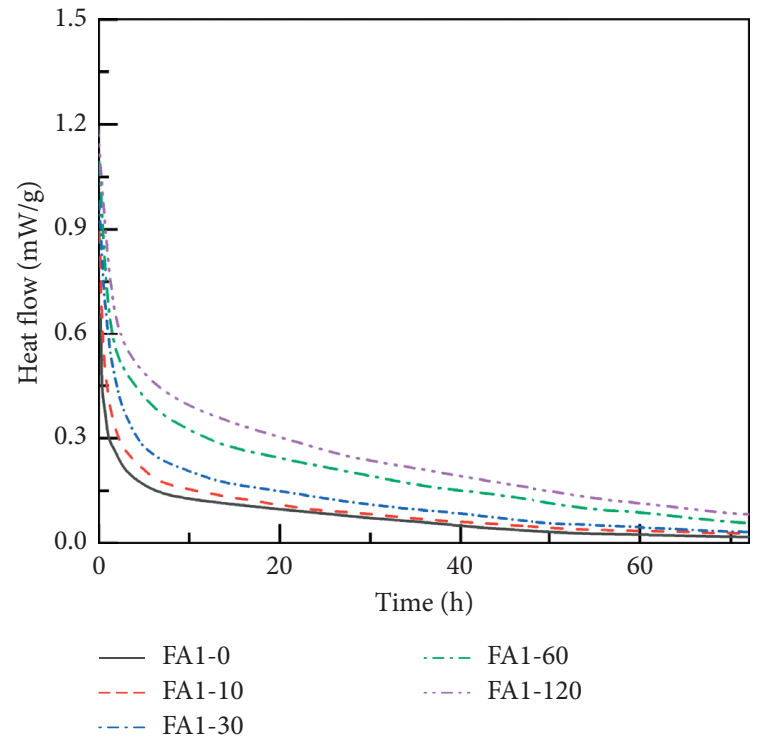

(a)

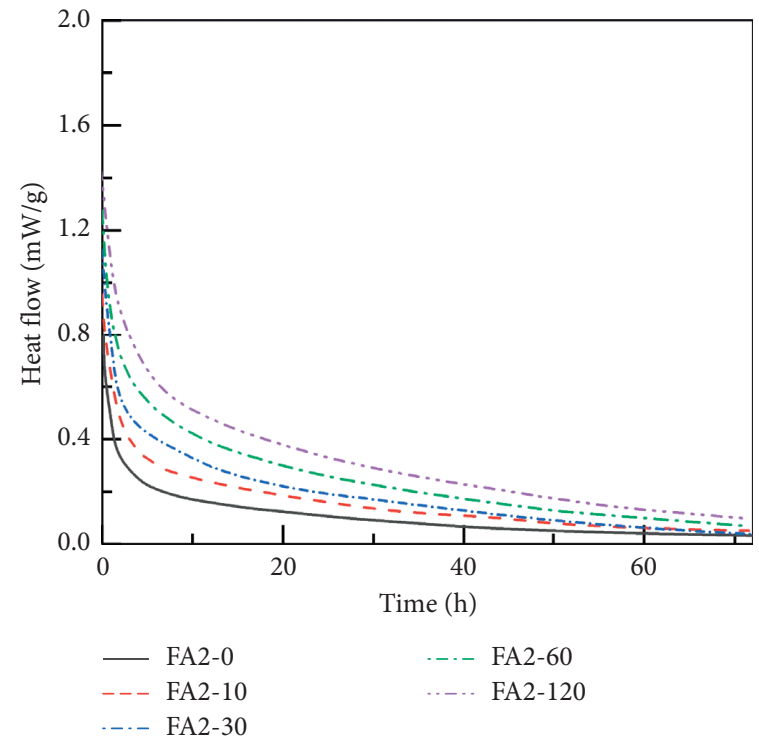

(b)

Figure 7: Continued. 


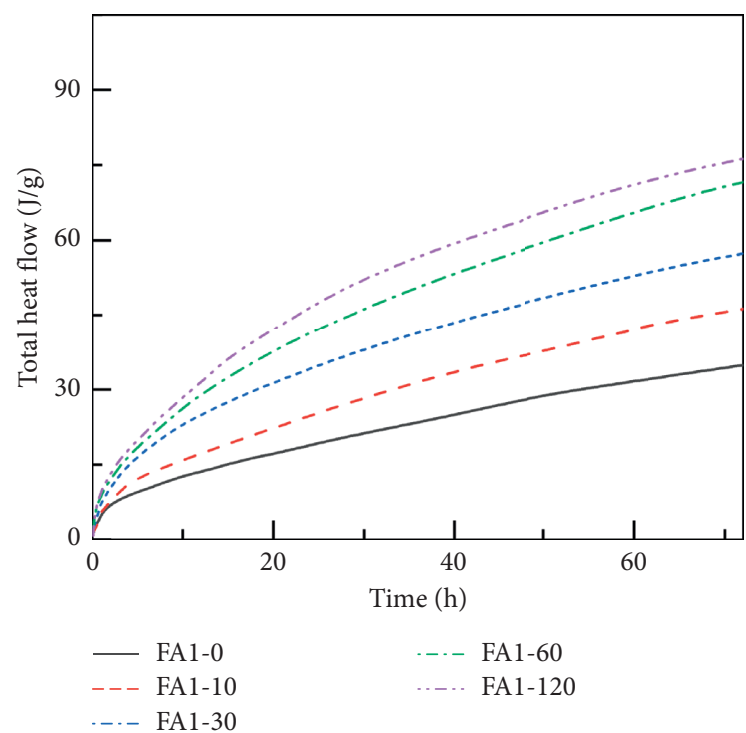

(c)

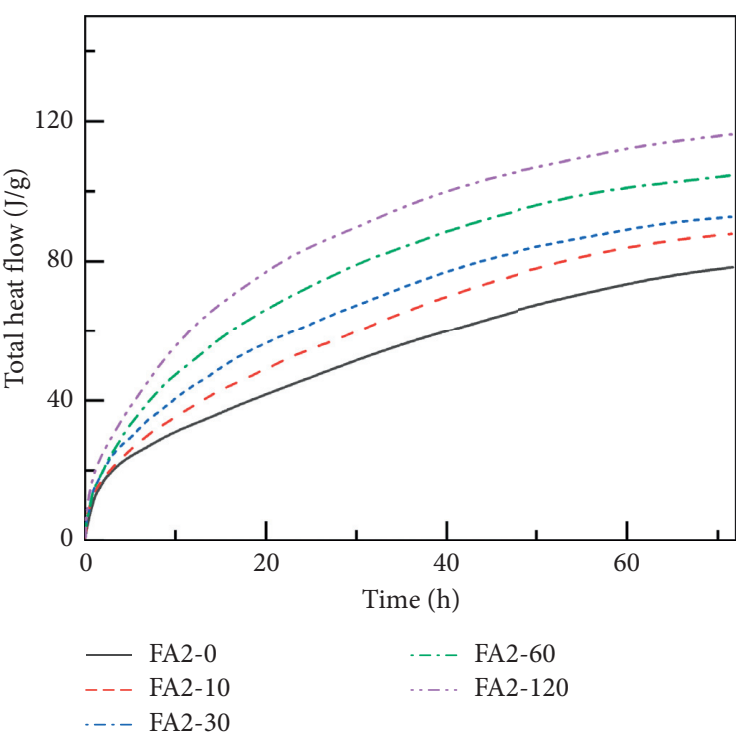

(d)

Figure 7: Calorimetry test results: $(a, b)$ heat flow rate and $(c, d)$ cumulative heat release.

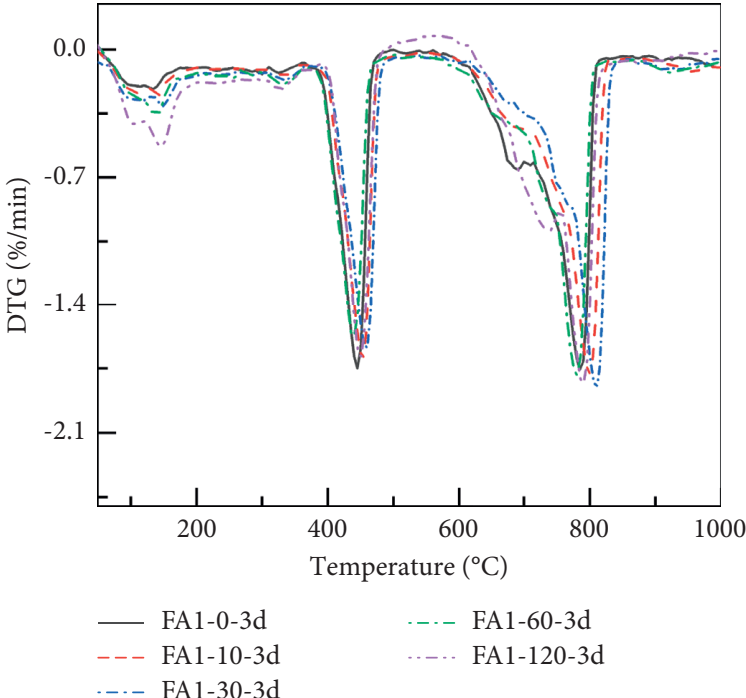

(a)

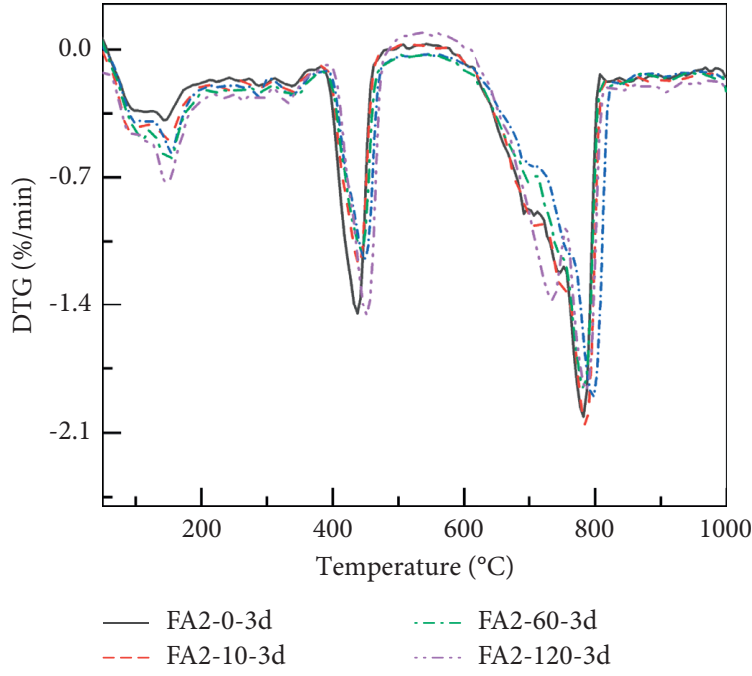

(b)

Figure 8: DTG analysis results of the hydrated samples after three days: (a) FA1 and (b) FA2.

hardened CPB samples could be divided into micropores $(<20 \mathrm{~nm})$, mesopores $(20-500 \mathrm{~nm})$, and macropores $(>500 \mathrm{~nm})$ [65]. Mesopores were the dominant pores in all the investigated samples. Besides, the mesopores and macropores decreased with the wet-grinding time, accompanied by the increase in the micropores. This led to the decrease in the total porosity. Generally, hydration gels from the cement reaction fill interparticle voids, leading to decreased porosity. The raw FA showed less reactivity, leading to a lower content of hydration gels, and thus higher porosity [66, 67]. This is one of the reasons why the control presented the lowest strength. The effects of wet-grinding can be ternary: finer FA particles can fill the gaps of cement grains. This could then refine the pore characteristics of the hardened matrix. Second, the mechanically treated FA presented higher reactivity, contributing to the generation of much smaller hydration gels. Besides, the superfine particles can also act as hydration nucleation sites, promoting the cement reaction. 

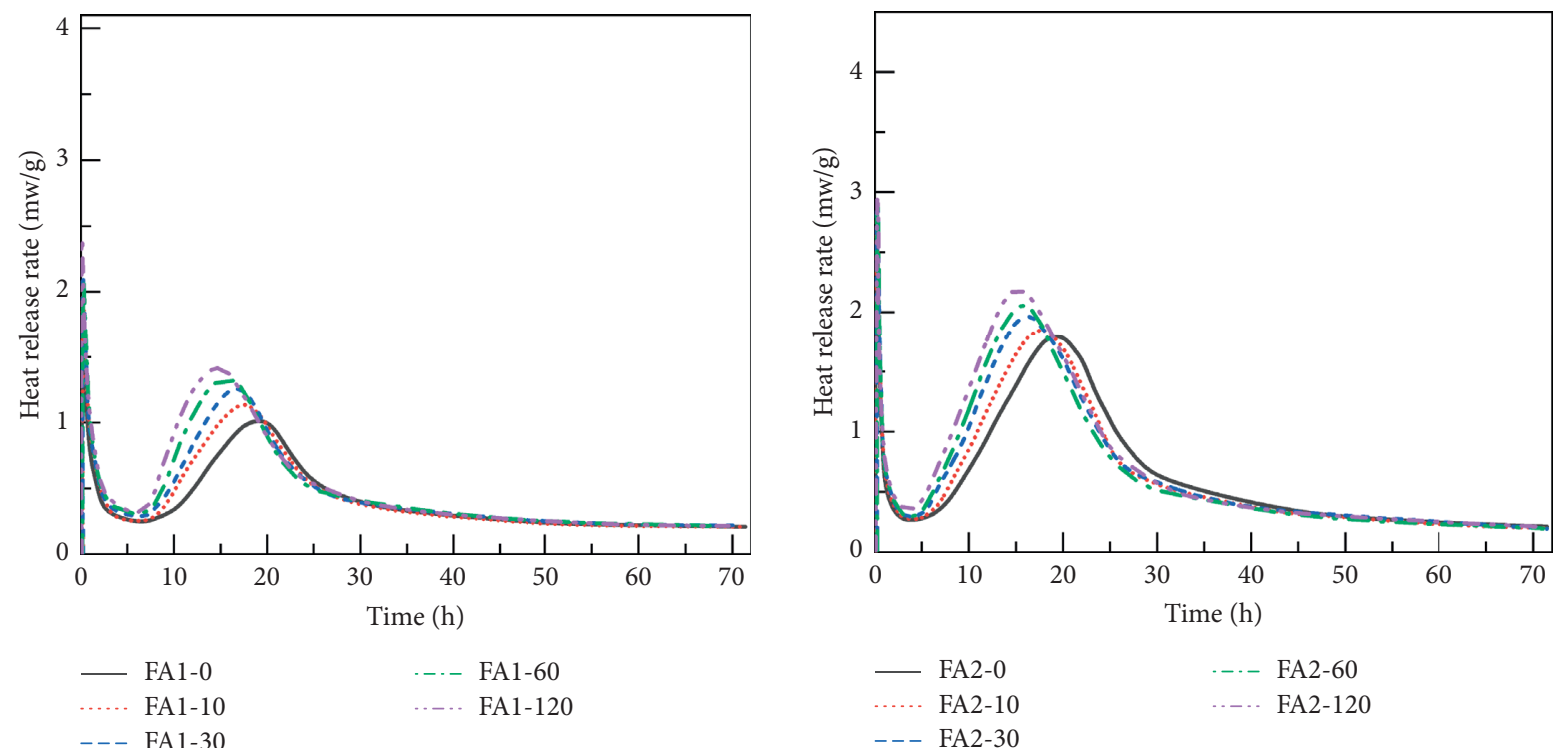

(a)

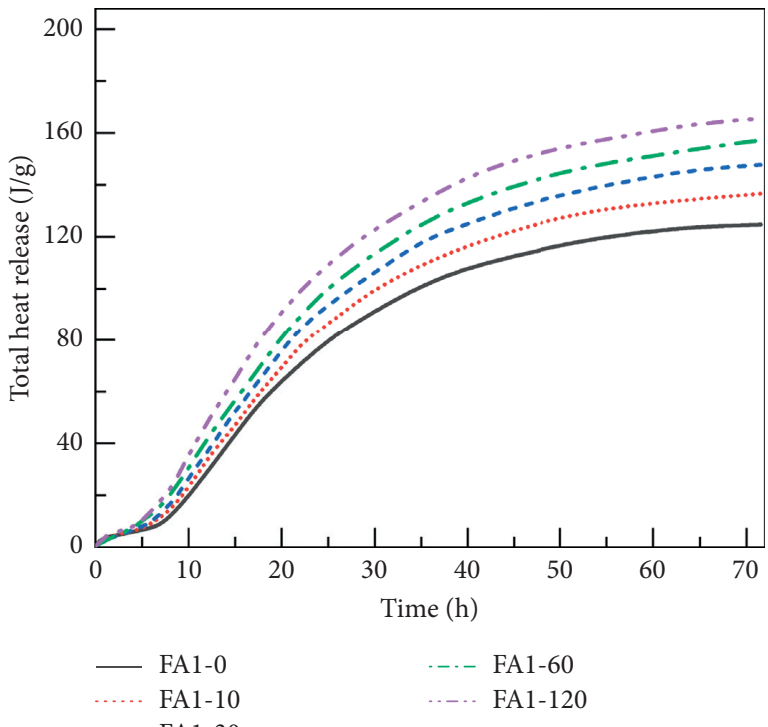

(c)

(b)

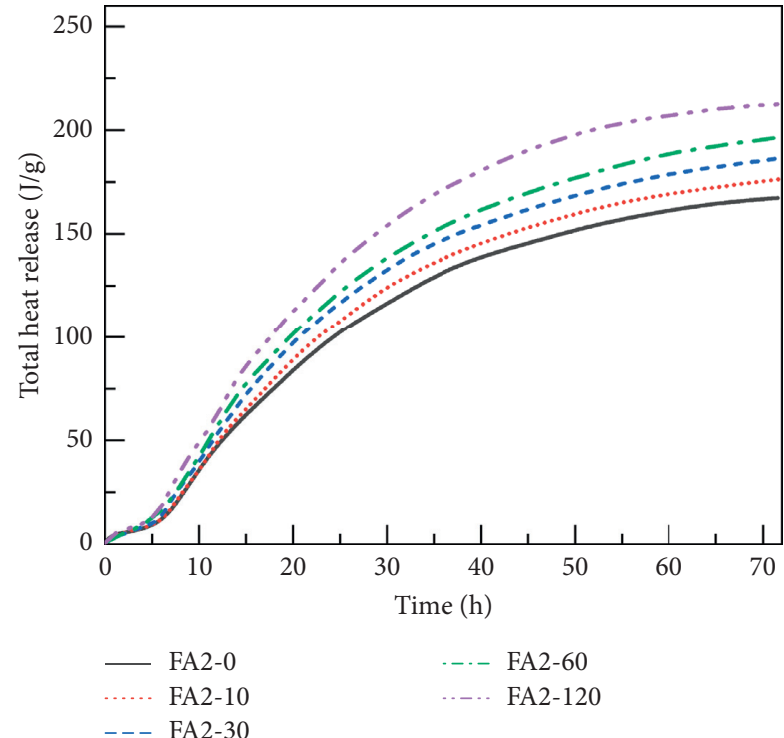

(d)

Figure 9: Calorimetry test results: $(a, b)$ heat flow rate and $(c, d)$ cumulative heat release.

TABLE 4: Kinetic data for the all the composites.

\begin{tabular}{|c|c|c|c|c|}
\hline Samples & $R_{\max }(\mathrm{mW} / \mathrm{g})$ & $t_{1}$ (hours) & $t_{2}$ (hours) & Cumulative heat release $(\mathrm{J} / \mathrm{g})$ \\
\hline FA1-0 & 1.01 & 8.22 & 19.29 & 124.54 \\
\hline FA1-10 & 1.12 & 7.68 & 17.93 & 136.54 \\
\hline FA1-30 & 1.26 & 7.32 & 16.84 & 146.96 \\
\hline FA1-60 & 1.33 & 7.04 & 15.76 & 157.38 \\
\hline FA1-120 & 1.41 & 6.86 & 14.58 & 165.50 \\
\hline FA2-0 & 1.81 & 5.68 & 19.47 & 167.08 \\
\hline FA2-10 & 1.86 & 4.78 & 17.92 & 176.42 \\
\hline FA2-30 & 1.97 & 4.42 & 16.30 & 186.57 \\
\hline FA2-60 & 2.06 & 4.15 & 15.84 & 196.73 \\
\hline FA2-120 & 2.19 & 3.78 & 15.04 & 212.55 \\
\hline
\end{tabular}

$R_{\max }$ is the maximum heat release rate, $t_{1}$ is the ending time of the induction period, and $t_{2}$ is the time reaching the main hydration peak. 


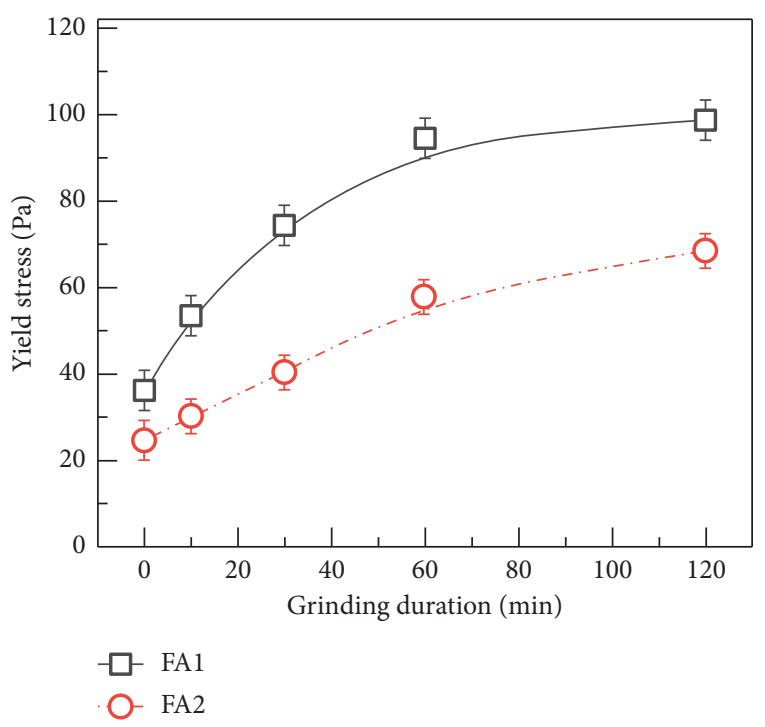

(a)

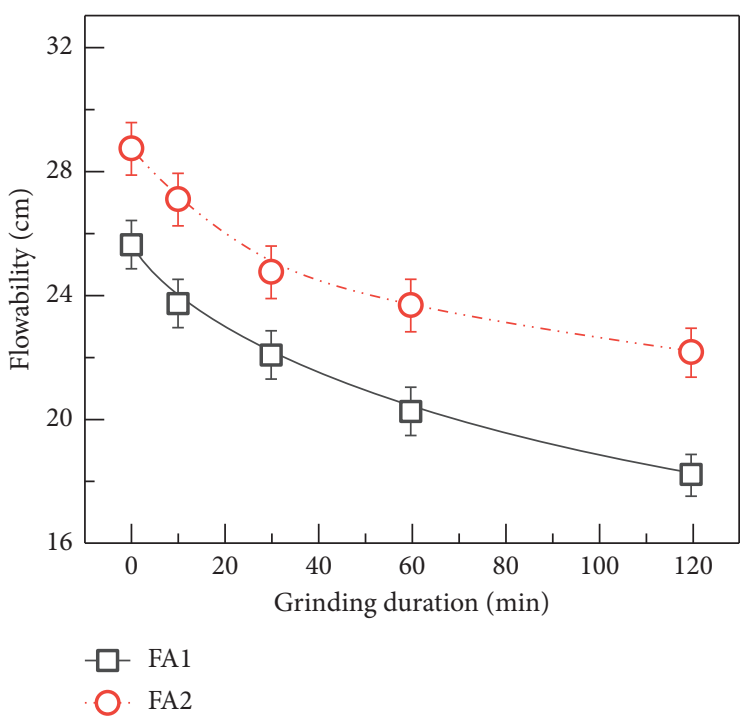

(b)

FIgURE 10: Rheological properties of the fresh slurry: (a) yield stress and (b) flowability.

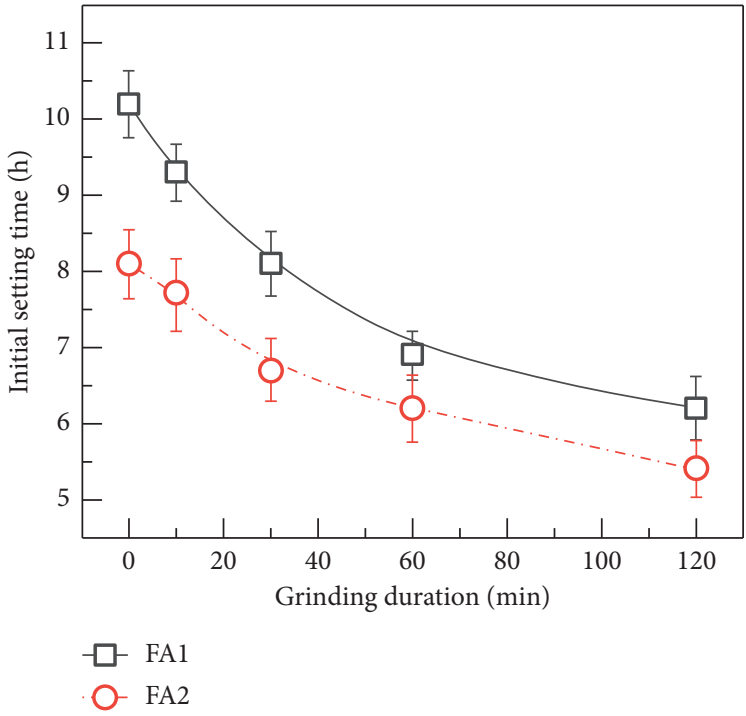

(a)

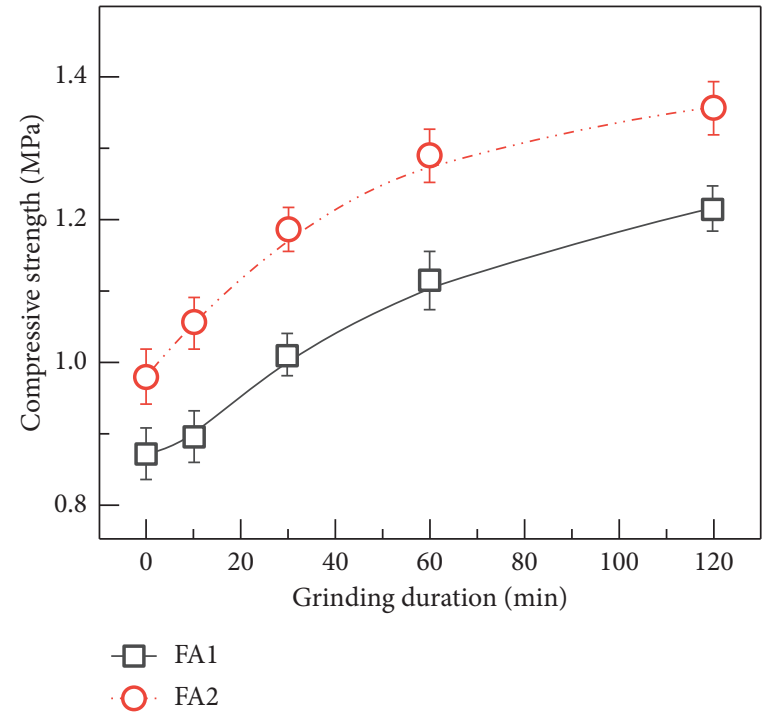

(b)

FIgURE 11: Initial setting time (a) and $28 \mathrm{~d}$ compressive strength (b). 


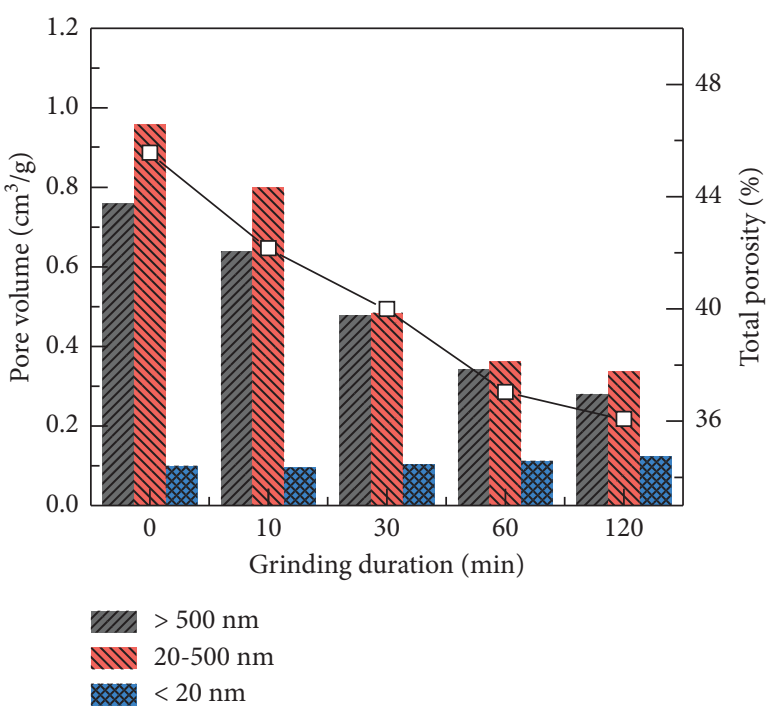

(a)

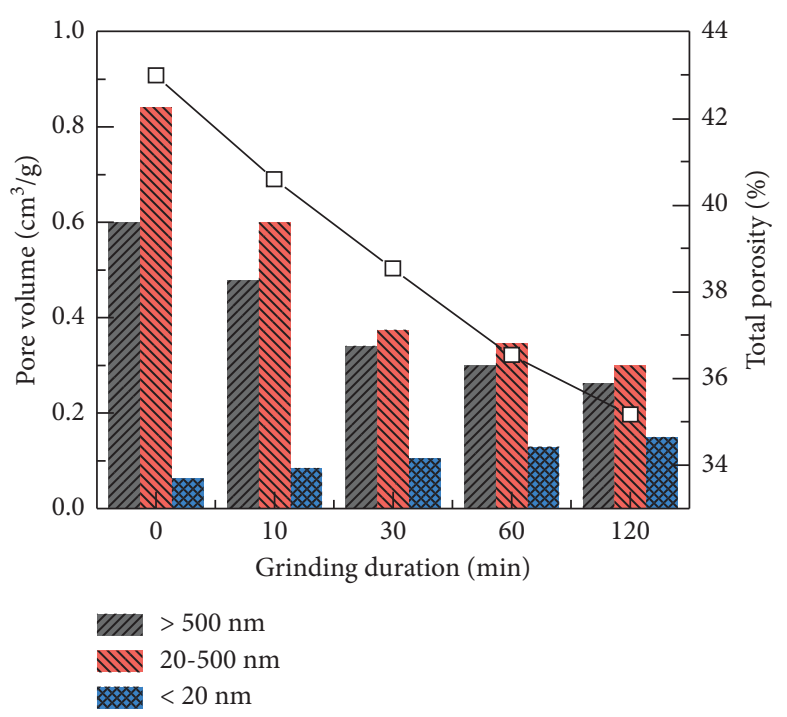

(b)

Figure 12: Pore structure of the samples after curing for $28 \mathrm{~d}$ : (a) FA1 and (b) FA2.

\section{Conclusion}

The low reactivity of FA limited its wide utilization in preparation of binder for cemented paste backfill (CPB). In the present work, FA was mechanically activated via wet-grinding with the aim of increasing its pozzolanic reactivity. The effect of wet-grinding was also investigated by dissolution and pozzolanic test. After that, the properties of CPB samples prepared using wet-ground FA was investigated. The results can lead to the following conclusions.

(1) Wet-grinding could decrease the particle size of FA to a more uniform distribution, with the increase in the specific surface area. This was accompanied by the content of crystalline phases in FA.

(2) The pozzolanic reactivity of wet-ground FA was increased according to the dissolution and pozzolanic tests. Wet-grinding promoted the dissolution of FA under alkaline conditions; at the same time, more hydration gels were formed during the pozzolanic test.

(3) Mechanical activation of FA increased the yield stress of the $\mathrm{CPB}$ slurry and then decreased the followability. The microstructure of FA showed a great impact on the rheological properties of $\mathrm{CPB}$ slurry.

(4) Mechanical activation of FA promoted the fast setting of the CPB samples. The reduction of the initial setting time was approximately $39.2 \%$ and $33.3 \%$ when the FA was ground for $120 \mathrm{~h}$.

(5) Compressive strength of CPB samples after curing for 28 days increased by around $62.5 \%$ and $38.8 \%$ when adding the mechanically ground FA1 and FA2 for $120 \mathrm{~min}$.

\section{Data Availability}

The data used to support the findings of this study are available from the corresponding author upon request.

\section{Conflicts of Interest}

The authors declare that they have no conflicts of interest.

\section{Acknowledgments}

This work was financially supported by the Study on Identification of Key Characteristic Variables for Stability of Chamber Group in Underground Concentrator, 02-1922.

\section{References}

[1] J. Shi, W. Huang, H. Han, and C. Xu, "Pollution control of wastewater from the coal chemical industry in China: environmental management policy and technical standards," Renewable and Sustainable Energy Reviews, vol. 143, Article ID 110883, 2021.

[2] L. Xue, W. Zhang, Z. Zheng et al., "Measurement and influential factors of the efficiency of coal resources of China's provinces: based on Bootstrap-DEA and Tobit," Energy, vol. 221, Article ID 119763, 2021.

[3] C. Fan, S. Guo, and H. Jin, "Numerical study on coal gasification in supercritical water fluidized bed and exploration of complete gasification under mild temperature conditions," Chemical Engineering Science, vol. 206, pp. 134-145, 2019.

[4] A. Bagheri, A. Nazari, J. G. Sanjayan, P. Rajeev, and W. Duan, "Fly ash-based boroaluminosilicate geopolymers: experimental and molecular simulations," Ceramics International, vol. 43, no. 5, pp. 4119-4126, 2017.

[5] C. Bobirică, J.-H. Shim, and J.-Y. Park, "Leaching behavior of fly ash-waste glass and fly ash-slag-waste glass-based geopolymers," Ceramics International, vol. 44, pp. 5886-5893, 2018. 
[6] P. Duan, C. Yan, W. Zhou, and D. Ren, "Development of fly ash and iron ore tailing based porous geopolymer for removal of $\mathrm{Cu}(\mathrm{II})$ from wastewater," Ceramics International, vol. 42, no. 12, pp. 13507-13518, 2016.

[7] A. F. Abdalqader, F. Jin, and A. Al-Tabbaa, "Development of greener alkali-activated cement: utilisation of sodium carbonate for activating slag and fly ash mixtures," Journal of Cleaner Production, vol. 113, pp. 66-75, 2016.

[8] J. Cheung, A. Jeknavorian, L. Roberts, and D. Silva, "Impact of admixtures on the hydration kinetics of Portland cement," Cement and Concrete Research, vol. 41, no. 12, pp. 1289-1309, 2011.

[9] B. Guo, S. Nakama, Q. Tian, N. D. Pahlevi, Z. Hu, and K. Sasaki, "Suppression processes of anionic pollutants released from fly ash by various Ca additives," Journal of Hazardous Materials, vol. 371, pp. 474-483, 2019.

[10] Q. Tian, B. Guo, S. Nakama, L. Zhang, Z. Hu, and K. Sasaki, "Reduction of undesirable element leaching from fly ash by adding hydroxylated calcined dolomite," Waste Management, vol. 86, pp. 23-35, 2019.

[11] S. K. Pandey and T. Bhattacharya, "Mobility, ecological risk and change in surface morphology during sequential chemical extraction of heavy metals in fly ash: a case study," Environmental Technology \& Innovation, vol. 13, pp. 373-382, 2019.

[12] D. P. Bentz, "Activation energies of high-volume fly ash ternary blends: hydration and setting," Cement and Concrete Composites, vol. 53, pp. 214-223, 2014.

[13] O. A. Abdulkareem, A. M. Mustafa Al Bakri, H. Kamarudin, I. Khairul Nizar, and A. E. A. Saif, "Effects of elevated temperatures on the thermal behavior and mechanical performance of fly ash geopolymer paste, mortar and lightweight concrete," Construction and Building Materials, vol. 50, pp. 377-387, 2014.

[14] T. Phoo-ngernkham, C. Phiangphimai, D. Intarabut et al., "Low cost and sustainable repair material made from alkaliactivated high-calcium fly ash with calcium carbide residue," Construction and Building Materials, vol. 247, Article ID 118543, 2020.

[15] D. Adak, M. Sarkar, and S. Mandal, "Structural performance of nano-silica modified fly-ash based geopolymer concrete," Construction and Building Materials, vol. 135, pp. 430-439, 2017.

[16] Y. Li, X. Liu, Z. Li, Y. Ren, Y. Wang, and W. Zhang, "Preparation, characterization and application of red mud, fly ash and desulfurized gypsum based eco-friendly road base materials," Journal of Cleaner Production, vol. 284, Article ID 124777, 2021.

[17] I. Phummiphan, S. Horpibulsuk, T. Phoo-ngernkham, A. Arulrajah, and S.-L. Shen, "Marginal lateritic soil stabilized with calcium carbide residue and fly ash geopolymers as a sustainable pavement base material," Journal of Materials in Civil Engineering, vol. 29, Article ID 4016195, 2017.

[18] I. Cavusoglu, E. Yilmaz, and A. O. Yilmaz, "Sodium silicate effect on setting properties, strength behavior and microstructure of cemented coal fly ash backfill," Powder Technology, vol. 384, pp. 17-28, 2021.

[19] Y.-g. Chen, L.-l. Guan, S.-y. Zhu, and W.-j. Chen, "Foamed concrete containing fly ash: properties and application to backfilling," Construction and Building Materials, vol. 273, Article ID 121685, 2021.

[20] M. Mahedi, B. Cetin, and A. Y. Dayioglu, "Effect of cement incorporation on the leaching characteristics of elements from fly ash and slag treated soils," Journal of Environmental Management, vol. 253, Article ID 109720, 2020.

[21] P. Pongsopha, P. Sukontasukkul, T. Phoo-ngernkham, T. Imjai, P. Jamsawang, and P. Chindaprasirt, "Use of burnt clay aggregate as phase change material carrier to improve thermal properties of concrete panel," Case Studies in Construction Materials, vol. 11, Article ID e00242, 2019.

[22] M. I. M. Alzeer and K. J. D. MacKenzie, "Synthesis and catalytic properties of new sustainable aluminosilicate heterogeneous catalysts derived from fly ash," ACS Sustainable Chemistry \& Engineering, vol. 6, no. 4, pp. 5273-5282, 2018.

[23] H. Rui, L. Zhang, L. Li, and L. zhu, "Solvent extraction of lithium from hydrochloric acid leaching solution of highalumina coal fly ash," Chemical Physics Letters, vol. 771, Article ID 138510, 2021.

[24] S. Donatello, A. Palomo, and A. Fernández-Jiménez, "Durability of very high volume fly ash cement pastes and mortars in aggressive solutions," Cement and Concrete Composites, vol. 38, pp. 12-20, 2013.

[25] F. Moghaddam, V. Sirivivatnanon, and K. Vessalas, "The effect of fly ash fineness on heat of hydration, microstructure, flow and compressive strength of blended cement pastes," Case Studies in Construction Materials, vol. 10, Article ID e00218, 2019.

[26] A. K. H. Kwan and J. J. Chen, "Adding fly ash microsphere to improve packing density, flowability and strength of cement paste," Powder Technology, vol. 234, pp. 19-25, 2013.

[27] Q. Zeng, K. Li, T. Fen-chong, and P. Dangla, "Determination of cement hydration and pozzolanic reaction extents for flyash cement pastes," Construction and Building Materials, vol. 27, no. 1, pp. 560-569, 2012.

[28] Y. Zhao, Q. Jingping, M. A. Zhengyu, G. Zhenbang, and L. Hui, "Effect of superfine blast furnace slags on the binary cement containing high-volume fly ash," Powder Technology, vol. 375, pp. 539-548, 2020.

[29] J. Yang, Y. Su, X. He et al., "Pore structure evaluation of cementing composites blended with coal by-products: calcined coal gangue and coal fly ash," Fuel Processing Technology, vol. 181, pp. 75-90, 2018.

[30] K. Yildirim and M. Sümer, "Effects of sodium chloride and magnesium sulfate concentration on the durability of cement mortar with and without fly ash," Composites Part B: Engineering, vol. 52, pp. 56-61, 2013.

[31] R. Kumar, S. Kumar, and S. P. Mehrotra, "Towards sustainable solutions for fly ash through mechanical activation," Resources, Conservation and Recycling, vol. 52, no. 2, pp. 157-179, 2007.

[32] C. Qi and A. Fourie, "Cemented paste backfill for mineral tailings management: review and future perspectives," Minerals Engineering, vol. 144, Article ID 106025, 2019.

[33] H. Jiang, Z. Qi, E. Yilmaz, J. Han, J. Qiu, and C. Dong, "Effectiveness of alkali-activated slag as alternative binder on workability and early age compressive strength of cemented paste backfills," Construction and Building Materials, vol. 218, pp. 689-700, 2019.

[34] V. D. Cao, S. Pilehvar, C. Salas-Bringas et al., "Influence of microcapsule size and shell polarity on the time-dependent viscosity of geopolymer paste," Industrial \& Engineering Chemistry Research, vol. 57, no. 29, pp. 9457-9464, 2018.

[35] J. Qiu, Y. Zhao, J. Xing, and X. Sun, "Fly ash/blast furnace slag-based geopolymer as a potential binder for mine backfilling: effect of binder type and activator concentration," Advances in Materials Science and Engineering, vol. 2019, Article ID 2028109, 12 pages, 2019. 
[36] W. Liu, Z. Guo, C. Wang, and S. Niu, "Physico-mechanical and microstructure properties of cemented coal Gangue-Fly ash backfill: effects of curing temperature," Construction and Building Materials, vol. 299, Article ID 124011, 2021.

[37] I. Cavusoglu, E. Yilmaz, and A. O. Yilmaz, "Additivity effect on properties of cemented coal fly ash backfill containing water-reducing admixtures," Construction and Building Materials, vol. 267, Article ID 121021, 2021.

[38] Y. Zhao, J. Qiu, Z. Ma, and X. Sun, "Eco-friendly treatment of coal gangue for its utilization as supplementary cementitious materials," Journal of Cleaner Production, vol. 285, Article ID 124834, 2021.

[39] Y. Cheng, F. Huang, W. Li, R. Liu, G. Li, and J. Wei, "Test research on the effects of mechanochemically activated iron tailings on the compressive strength of concrete," Construction and Building Materials, vol. 118, pp. 164-170, 2016.

[40] P. L. Guzzo, F. B. Marinho de Barros, B. R. Soares, and J. B. Santos, "Evaluation of particle size reduction and agglomeration in dry grinding of natural quartz in a planetary ball mill," Powder Technology, vol. 368, pp. 149-159, 2020.

[41] S. Kucharczyk, M. Sitarz, M. Zajac, and J. Deja, "The effect of $\mathrm{CaO} / \mathrm{SiO} 2$ molar ratio of $\mathrm{CaO}-\mathrm{Al} 2 \mathrm{O} 3-\mathrm{SiO} 2$ glasses on their structure and reactivity in alkali activated system," Spectrochimica Acta Part A: Molecular and Biomolecular Spectroscopy, vol. 194, pp. 163-171, 2018.

[42] S. Kucharczyk, M. Zajac, C. Stabler et al., "Structure and reactivity of synthetic $\mathrm{CaO}-\mathrm{Al}_{2} \mathrm{O}_{3}-\mathrm{SiO}_{2}$ glasses," Cement and Concrete Research, vol. 120, pp. 77-91, 2019.

[43] ASTM C191-13, Standard Test Methods for Time of Setting of Hydraulic Cement by Vicat Needle, ASTM Committee C01, West Conshohocken, PA, USA, 2013.

[44] Z. Giergiczny, "Fly ash and slag," Cement and Concrete Research, vol. 124, Article ID 105826, 2019.

[45] A. A. Siyal, M. R. Shamsuddin, N. E. Rabat, M. Zulfiqar, Z. Man, and A. Low, "Fly ash based geopolymer for the adsorption of anionic surfactant from aqueous solution," Journal of Cleaner Production, vol. 229, pp. 232-243, 2019.

[46] J. Yang, J. Huang, Y. Su et al., "Eco-friendly treatment of lowcalcium coal fly ash for high pozzolanic reactivity: a step towards waste utilization in sustainable building material," Journal of Cleaner Production, vol. 238, Article ID 117962, 2019.

[47] H. Niu, P. Kinnunen, H. Sreenivasan, E. Adesanya, and M. Illikainen, "Structural collapse in phlogopite mica-rich mine tailings induced by mechanochemical treatment and implications to alkali activation potential," Minerals Engineering, vol. 151, Article ID 106331, 2020.

[48] N. Garg and J. Skibsted, "Dissolution kinetics of calcined kaolinite and montmorillonite in alkaline conditions: evidence for reactive $\mathrm{Al}(\mathrm{V})$ sites," Journal of the American Ceramic Society, vol. 102, no. 12, pp. 7720-7734, 2019.

[49] C. Kuenzel and N. Ranjbar, "Dissolution mechanism of fly ash to quantify the reactive aluminosilicates in geopolymerisation," Resources, Conservation and Recycling, vol. 150, Article ID 104421, 2019.

[50] M. Liu, H. Tan, and X. He, "Effects of nano-SiO2 on early strength and microstructure of steam-cured high volume fly ash cement system," Construction and Building Materials, vol. 194, pp. 350-359, 2019.

[51] H. C. Pedrosa, O. M. Reales, V. D. Reis, M. d. D. Paiva, and E. M. R. Fairbairn, "Hydration of Portland cement accelerated by C-S-H seeds at different temperatures," Cement and Concrete Research, vol. 129, Article ID 105978, 2020.
[52] G. Land and D. Stephan, "The effect of synthesis conditions on the efficiency of C-S-H seeds to accelerate cement hydration," Cement and Concrete Composites, vol. 87, pp. 73-78, 2018.

[53] F. Zou, C. Hu, F. Wang, Y. Ruan, and S. Hu, "Enhancement of early-age strength of the high content fly ash blended cement paste by sodium sulfate and C-S-H seeds towards a greener binder," Journal of Cleaner Production, vol. 244, Article ID 118566, 2020.

[54] S. Fan, B. Cao, N. Deng, Y. Hu, and M. Li, "Effects of ferrihydrite nanoparticle incorporation in cementitious materials on radioactive waste immobilization," Journal of Hazardous Materials, vol. 379, Article ID 120570, 2019.

[55] D. Siang Ng, S. C. Paul, V. Anggraini et al., "Influence of SiO2, $\mathrm{TiO} 2$ and $\mathrm{Fe} 2 \mathrm{O} 3$ nanoparticles on the properties of fly ash blended cement mortars," Construction and Building Materials, vol. 258, Article ID 119627, 2020.

[56] S. Zhang, L. Yang, F. Ren, J. Qiu, and H. Ding, "Rheological and mechanical properties of cemented foam backfill: effect of mineral admixture type and dosage," Cement and Concrete Composites, vol. 112, Article ID 103689, 2020.

[57] J. Haiqiang, M. Fall, and L. Cui, "Yield stress of cemented paste backfill in sub-zero environments: experimental results," Minerals Engineering, vol. 92, pp. 141-150, 2016.

[58] Z. Li, T.-a. Ohkubo, and Y. Tanigawa, "Theoretical analysis of time-dependence and thixotropy of fluidity for high fluidity concrete," Journal of Materials in Civil Engineering, vol. 16, no. 3, pp. 247-256, 2004.

[59] X. Chen, X. Shi, J. Zhou, X. Du, Q. Chen, and X. Qiu, "Effect of overflow tailings properties on cemented paste backfill," Journal of Environmental Management, vol. 235, pp. 133-144, 2019.

[60] C. Qi, A. Fourie, Q. Chen, and Q. Zhang, “A strength prediction model using artificial intelligence for recycling waste tailings as cemented paste backfill," Journal of Cleaner Production, vol. 183, pp. 566-578, 2018.

[61] M. Fall, D. Adrien, J. C. Célestin, M. Pokharel, and M. Touré, "Saturated hydraulic conductivity of cemented paste backfill," Minerals Engineering, vol. 22, no. 15, pp. 1307-1317, 2009.

[62] S. Zhang, F. Ren, Z. Guo, J. Qiu, and H. Ding, "Strength and deformation behavior of cemented foam backfill in sub-zero environment," Journal of Materials Research and Technology, vol. 9, no. 4, pp. 9219-9231, 2020.

[63] B. Lothenbach, K. Scrivener, and R. D. Hooton, "Supplementary cementitious materials," Cement and Concrete Research, vol. 41, no. 12, pp. 1244-1256, 2011.

[64] S. Zhang, F. Ren, Y. Zhao, J. Qiu, and Z. Guo, "The effect of stone waste on the properties of cemented paste backfill using alkali-activated slag as binder," Construction and Building Materials, vol. 283, Article ID 122686, 2021.

[65] W. Xu, Y. Zhang, and B. Liu, "Influence of silica fume and low curing temperature on mechanical property of cemented paste backfill," Construction and Building Materials, vol. 254, Article ID 119305, 2020.

[66] W. Xu, Y. Zhang, X. Zuo, and M. Hong, "Time-dependent rheological and mechanical properties of silica fume modified cemented tailings backfill in low temperature environment," Cement and Concrete Composites, vol. 114, Article ID 103804, 2020.

[67] W. Xu, W. Chen, M. Tian, and L. Guo, "Effect of temperature on time-dependent rheological and compressive strength of fresh cemented paste backfill containing flocculants," Construction and Building Materials, vol. 267, Article ID 121038, 2021. 